\title{
Pochonia chlamydosporia Isolate PC-170-Induced Expression of Marker Genes for Defense Pathways in Tomatoes Challenged by Different Pathogens
}

\author{
Xia Zhuang ${ }^{1,2,+}$, Jian-Long Zhao ${ }^{2,+} \oplus$, Miao Bai ${ }^{1,+}{ }^{+}$Xing-Xing Ping ${ }^{2}$, Yan-Lin Li ${ }^{1} \oplus$, Yu-Hong Yang ${ }^{2}$, \\ Zhen-Chuan Mao ${ }^{2}$, Guo-Shun Yang ${ }^{1, *}$ and Bing-Yan Xie ${ }^{2, *}$ \\ 1 Engineering Research Center for Horticultural Crop Germplasm Creation and New Variety Breeding of \\ Ministry of Education, College of Horticulture, Hunan Agricultural University, Changsha 410128, China; \\ zhuangxiami@yeah.net (X.Z.); baimiao@hunau.edu.cn (M.B.); liyanlin@hunau.edu.cn (Y.-L.L.) \\ 2 The Institute of Vegetables and Flowers, Chinese Academy of Agricultural Sciences, Beijing 100081, China; \\ zhaojianlong@caas.cn (J.-L.Z.); pxx13663441748@163.com (X.-X.P.); yangyuhong@caas.cn (Y.-H.Y.); \\ maozhenchuan@caas.cn (Z.-C.M.) \\ * Correspondence: guoshunyang@aliyun.com (G.-S.Y.); xiebingyan@caas.cn (B.-Y.X.) \\ $+\quad$ Xia Zhuang, Jian-Long Zhao and Miao Bai should be considered joint first author.
}

\section{check for} updates

Citation: Zhuang, X.; Zhao, J.-L.; Bai, M.; Ping, X.-X.; Li, Y.-L.; Yang, Y.-H.; Mao, Z.-C.; Yang, G.-S.; Xie, B.-Y. Pochonia chlamydosporia Isolate PC-170-Induced Expression of Marker Genes for Defense Pathways in Tomatoes Challenged by Different Pathogens. Microorganisms 2021, 9 , 1882. https://doi.org/10.3390/ microorganisms 9091882

Academic Editor: Kris Audenaert

Received: 2 August 2021

Accepted: 31 August 2021

Published: 5 September 2021

Publisher's Note: MDPI stays neutral with regard to jurisdictional claims in published maps and institutional affiliations.

Copyright: (c) 2021 by the authors. Licensee MDPI, Basel, Switzerland. This article is an open access article distributed under the terms and conditions of the Creative Commons Attribution (CC BY) license (https:/ / creativecommons.org/licenses/by/ $4.0 /)$.

\begin{abstract}
Pochonia chlamydosporia is a fungal parasite of nematode eggs. Studies have shown that some strains of Pochonia chlamydosporia can promote plant growth and induce plants' systemic resistance to root-knot nematodes by colonizing in their roots. This study aimed to verify the effect of the PC-170 strain on tomato growth and systemic resistance. Split-root experiments were conducted to observe the systemic resistance induced by PC-170. To explore the defense pathway that was excited due to the colonization by PC-170, we tested the expression of marker genes for defense pathways, and used mutant lines to verify the role of plant defense pathways. Our results showed that PC-170 can colonize roots, and promotes growth. We found a role for jasmonic acid (JA) in modulating tomato colonization by PC-170. PC-170 can activate tomato defense responses to reduce susceptibility to infection by the root-knot nematode Meloidogyne incognita, and induced resistance to some pathogens in tomatoes. The marker genes of the defense pathway were significantly induced after PC-170 colonization. However, salicylic acid (SA)- and jasmonic acid (JA)-dependent defenses in roots were variable with the invasion of different pathogens. Defense pathways play different roles at different points in time. SA- and JA-dependent defense pathways were shown to cross-communicate. Different phytohormones have been involved in tomato plants' responses against different pathogens. Our study confirmed that adaptive JA signaling is necessary to regulate PC-170 colonization and induce systemic resistance in tomatoes.
\end{abstract}

Keywords: induced defenses; jasmonic acid (JA); Pochonia chlamydosporia; pathogen; root endophytes; salicylic acid (SA)

\section{Introduction}

Plants are constantly subjected to various attacks from phytopathogenic fungi, bacteria, and plant-parasitic nematodes. Plants are not entirely passive, because the plants themselves have a series of corresponding immune responses, and they benefit from endophytic fungi to modulate their interactions with pathogens. In recent decades, some thought-provoking plant innate immune models have been put forward, such as the 'Zigzag model' in 2006, which indicated that there was co-evolution between pathogens and plants [1]. The 'Invasion model' in 2015 described the symbiotic relationship between pathogens and plants [2], while the 'Spatial Immunity Model' in 2019 defined immune signaling in plant-microbe interactions [3]. In addition to the induction of immunity in plants by the recognition of pathogenic effectors in host cells, plant roots benefit from endophytic and mycorrhizal fungi, which can provide plant hosts with nutrition and 
protection from abiotic or biotic stresses [4]. For example, fungal endophytes improve seed germination, and promote root formation and plant growth by producing plant hormones such as indole-3-acetic acid (IAA) [5,6].

Pochonia chlamydosporia belongs to the Clavicipitaceae family [7,8], which has a natural inhibitory effect on plant-parasitic nematodes [9-11]. This fungus has been applied as a promising biological control agent of nematodes in many economically important crops $[9,12-14]$. It has been reported that $P$. chlamydosporia has the ability to colonize in the roots of both monocotyledonous and dicotyledonous plants, including barley [15], tomatoes [16], potatoes [17], and Arabidopsis thaliana [18]. Interestingly, P. chlamydosporia has also exhibited multiple functions in promoting plant growth $[9,19]$. Previous studies have shown that colonization of P. chlamydosporia in plant root systems promotes growth and increases yield [20,21]. Studies have confirmed the endophytic colonization of Arabidopsis by P. chlamydosporia, and its ability to induce beneficial traits [19]. Some studies have shown $P$. chlamydosporia to induce systemic resistance to Meloidogyne incognita in tomatoes, but other studies have indicated that this response is plant-species-dependent [22]. Recently, based on genome and secretome analysis of $P$. chlamydosporia, a number of secreted proteins have been identified that enabled a comprehensive understanding of the endogenous mechanisms and adaptive evolution of $P$. chlamydosporia [23]. Investigation of molecular mechanisms provided evidence that $P$. chlamydosporia induces plant defenses [24].

Phytohormones play essential roles during plant growth and development, and also coordinate the modulation of plant defenses [25]. Some studies have shown that endophytes accelerate the activation of plant defense responses when different pathogens attack plants. According to the various methods that activate different signaling pathways, the microorganism-activated resistance of plants is divided into two types: One is systemic acquired resistance (SAR), which is characterized by an early increase in endogenous salicylic acid (SA) and the accumulation of pathogenicity-related (PR) proteins. The other is inducible systemic resistance, which does not involve the expression of PR proteins, but is mediated through signaling pathways, in which the plant hormones jasmonic acid (JA) and ethylene (ET) play key roles [26]. Plants protect themselves from infection by biotrophic pathogens by activating SA-dependent signals; however, against necrotic pathogens that kill plant cells, and against chewing insects, JA-dependent signaling is generally effective [27]. Plant-parasitic nematodes penetrate into plant roots, migrate into the vascular system and, finally, establish feeding sites by recruiting the plant's developmental pathway, which involves hormonal crosstalk [28-30].

Around the time of hypersensitive response (HR) development, the levels of salicylic acid (SA) increase, along with the induction of various defense-associated genes, including the pathogenesis-related $(P R)$ genes. The non-expressor of $P R-1$ (NPR1) mutants are insensitive to SA, fail to develop SAR, and exhibit enhanced disease susceptibility. For this reason, the expression of $P R$ genes is frequently used as a marker of SAR development [31]. Pathogenesis-related protein-la $(P R-1 a)$ is a protein that is strongly induced during the onset of systemic acquired resistance (SAR) in tobacco [32]. The PR1b1 (also named PR-P6) gene is also strongly activated locally in tissues undergoing the hypersensitive response. Phenylalanine ammonia lyase $(P A L)$ catalyzes the deamination of phenylalanine to transcinnamic acid, and is the first rate-limiting enzyme in the phenylpropanoid metabolism pathway. The expression of the PAL gene marks the beginning of SA biosynthesis. Silencing or epigenetically suppressing $P A L$ genes inhibits the salicylate production, preventing the development of systemic acquired resistance in response to infection by the tobacco mosaic virus [33]. NPR1, which was identified in Arabidopsis through genetic screens for SARcompromised mutants, is an important transducer of the SA signal in disease resistance, and is essential for SA-induced $P R-1 a$ gene expression. NPR1 was reported as being a positive regulator of SA-dependent, defense-related gene expression, but negatively regulates JAresponsive gene expression [34]. Thus, NPR1 modulates crosstalk between salicylate- and jasmonate-dependent defense pathways. LoxD and OPR3 are JA biosynthesis genes. In the biosynthesis of jasmonic acid (JA), the lipoxygenases (LOX) are a group of enzymes 
responsible for converting both linoleic and linolenic acids into 9- and 13-hydroperoxides. $O P R s$ belong to a family of flavoproteins. OPR3 of tomato is a peroxisomal enzyme. The role of OPR3 in JA biosynthesis has been shown by genetic evidence provided by the JA-deficient mutants opr3 and dde1, both affected in OPR3. All genes encoding enzymes of JA biosynthesis are JA-inducible [35]. In response to wounding by insects or mechanical damage, plants synthesize multiple proteinase inhibitors with a wide range of specificities (e.g., wound-inducible serine proteinase inhibitors I and II, and cysteine proteinase protein inhibitors). Proteinase inhibitor II (PI II) and multicystatin $(M C)$ are the typical JA-regulated, wound-related genes.

Using the split-root test in tomatoes, studies suggest that both salicylic-acid- and jasmonic-acid-dependent signaling pathways have been proposed as being responsible for systemically induced resistance to Meloidogyne spp. [22,36,37]. Martínez-Medina [37] proposed that Trichoderma harzianum T-78 first induces the upregulation of salicylic-acid-related gene expression during nematode infection, followed by the induction of jasmonic-acidrelated gene expression. Some studies suggest specific and time-dependent relationships linking host plants and P. chlamydosporia in the presence of biotic stress factors, with colonization by P. chlamydosporia in plant roots being functional to a systemic, but complex, activation of defense genes [22,38]. In addition, evidence shows that jasmonic acid (JA) plays a key role in regulating root colonization by P. chlamydosporia. Similarly, it has been reported that $P$. chlamydosporia induces resistance to fungal disease and abiotic stress [15,39], via means such as the regulation of miRNAs in tomatoes [40], or regulation of the expression of plant defense genes relating to the salicylic acid (SA) and JA pathways in barley and Arabidopsis [7,18].

Therefore, further research on beneficial rhizosphere microorganisms (such as endophytes) is important. There have been studies on the interaction between P. chlamydosporia and other plants, but there are certain differences between different strains. P. chlamydosporia strain 170 (PC-170) was isolated from the root-knot nematode $M$. incognita [23]. This research aims to study the influence of PC-170 on defense systems during infection by rootknot nematodes and other pathogens. Tomato SA and JA mutant lines were used to explore the importance of defense pathways in the systemically induced resistance, which will broaden our knowledge on the working mechanisms of an important beneficial endophyte.

\section{Materials and Methods}

\subsection{Biological Material and Growth Conditions}

The PC-170 strain of P. chlamydosporia used in this study was isolated from Meloidogyne incognita eggs. The strain was stored in the CGMCC (China General Microbial Culture Collection Center) under the preservation number 8860 [41]. The PC-170 strain, and a stable green fluorescent protein (GFP)-expressing transformant (PC-170gfp) that was constructed via protoplast transformation [42], were cultured on potato dextrose agar (PDA)-medium plates in a $28^{\circ} \mathrm{C}$ incubator.

The tomato (Solanum lycopersicum) cultivars Lichun, Castlemart, and Moneymaker were used in this study. These tomato varieties are not resistant to nematodes or various other pathogens, and are classified as susceptible varieties. Additionally, the JAimpaired mutant def1 in the Castlemart background [43] and the SA-deficient line NahG in the Moneymaker background [44] were used. The DEF1 gene acts after lipoxygenase conversion of linolenic acid to hydroperoxylinolenic acid, but before the conversion of 12-oxo-phytodienoic acid (PDA) to JA. The def1 mutant is deficient in the DEF1 gene; thus, the octadecanoid pathway in the def1 mutant is blocked downstream of 13(S)hydroperoxylinolenic acid (HPLA) action, but upstream of 12-oxo-phytodienoic acid (PDA) action. $N a h G$ is a gene encoding salicylate hydroxylase that removes endogenous SA by converting it to catechol. The NahG mutant expressing the NahG gene, encoding salicylate hydroxylase, did not accumulate SA in response to intercellular infiltration with washing fluid. Tomato seeds were surface-sterilized with $2 \%$ sodium hypochlorite, thoroughly rinsed with sterile water, and then germinated for $10 \mathrm{~d}$ in soil at $25^{\circ} \mathrm{C}$. Then, tomato 
seedlings were transplanted into soil in different nutrition bowls in a greenhouse according to the experimental requirements. The soil used in all experiments was made of peat soil (KLASMANN876, Germany), perlite, and vermiculite mixed in a ratio of 2:1:1, and then sterilized at $121^{\circ} \mathrm{C}$ for $60 \mathrm{~min}$ after mixing. The plants received water according to their normal growth needs.

Tomato fusarium wilt (Fusarium oxysporum f.s p. lycopersici (Sacc.) Snyder and Hansen, TFW) was grown on PDA plates with rifampicin. Tomato bacterial wilt (Ralstonia solanacearum (Smith) Yabuuchi et al., TBW) was preserved in sterile distilled water. Cucumber mosaic virus (CMV) and tomato mosaic virus (ToMV) were stored in the laboratory, and were inoculated regularly on the leaves of tobacco (Nicotiana tabacum L.).

The long-term propagation of Meloidogyne incognita was carried out in a greenhouse with water spinach (Ipomoea aquatica Forssk.) as the growth material. We used tweezers to manually pick out the nematode eggs from the roots of the water spinach, disinfected them with $0.5 \%$ sodium hypochlorite, washed them with sterile water, collected them on a $25 \mu \mathrm{m}$ sieve on a $90 \mathrm{~mm}$ plate, and stored them at $25 \pm 2{ }^{\circ} \mathrm{C}$. The second stage juveniles (J2s) were collected from the filter with a pipette every day. The number of J2s collected for use was determined according to the needs of the experiment.

\subsection{Colonization of PC-170 on the Roots of Tomatoes}

\subsubsection{Inoculation Methods}

The tomato variety used in the experiment was Lichun. Inoculation methods included fungus cake inoculation and spore fluid inoculation. Fungus cake inoculation was performed by using a punch to remove a $1 \mathrm{~cm}$ cylindrical piece of fungus cake of the PC-170 strain growing on a PDA plate, which had been cultured in a $28^{\circ} \mathrm{C}$ incubator for 1 week, and then evenly burying four of these $1 \mathrm{~cm}$ fungus cake pieces in the rhizosphere of each tomato plant. The spore fluid inoculation was conducted by using sterile water to rinse the PDA plates inoculated with the PC-170 strain. The plates were rinsed several times to collect conidia that were growing on the PDA plates after culturing in an incubator at $28{ }^{\circ} \mathrm{C}$ for 1 week. Three different concentrations of spore liquid were used for inoculation: $5 \times 10^{2}$ spores $\cdot \mathrm{mL}^{-1}, 5 \times 10^{6}$ spores $\cdot \mathrm{mL}^{-1}$, and $5 \times 10^{10}$ spores $\cdot \mathrm{mL}^{-1}$. Each nutrient bowl was filled with $50 \mathrm{~g}$ of soil mixed with $20 \mathrm{~mL}$ of prepared spore solution before tomato transplantation.

\subsubsection{The Detection of Colonization}

To detect endophytic colonization, the roots of three plants were randomly selected at different time periods after the inoculation with PC-170, and then the roots were rinsed and disinfected with $1 \%$ sodium hypochlorite for $1 \mathrm{~min}$, washed three times in sterile distilled water, and blotted onto sterile paper. Roots were then cut into $1 \mathrm{~cm}$ fragments (10 fragments.plate ${ }^{-1}$ ) and plated in growth-restricting medium (PDA $39 \mathrm{~g} \cdot \mathrm{L}^{-1}, \mathrm{NaCl}$ $17.5 \mathrm{~g} \cdot \mathrm{L}^{-1}$, rose bengal $75 \mathrm{mg} \cdot \mathrm{L}^{-1}$, Geneticin (G418) $300 \mathrm{mg} \cdot \mathrm{L}^{-1}$, and $50 \mathrm{mg} \cdot \mathrm{L}^{-1}$ each of streptomycin sulfate and chloramphenicol). Total root colonization by P. chlamydosporia was evaluated using quantitative PCR (q-PCR). DNA was extracted from non-disinfected roots to assess total colonization, and the root material was collected. Roots $(1 \mathrm{~g})$ were freeze-dried and then ground in liquid nitrogen. Total DNA was extracted using the Plant Genomic DNA Kit (TIANGEN BIOTECH (BEIJING) CO., Ltd., Beijing, China). The DNA was quantified using a NanoDrop 2000C spectrophotometer (Thermo Scientific, Waltham, MA, USA). In qPCR experiments, tub1 primers were used to amplify a partial region of the tubulin gene of PC-170. Reactions were performed in $20 \mu \mathrm{L}$ with $50 \mathrm{ng}$ of root DNA, $500 \mathrm{nM}$ primers, and $1 \times$ SYBR Green Master Mix (TIANGEN BIOTECH (BEIJING) CO., Ltd.). All samples were diluted in 0.01\% DEPC-treated water. Reactions were performed in triplicate in a Thermal Cycling StepOnePlus using the following profile: $95^{\circ} \mathrm{C}$ for $15 \mathrm{~min}$, 40 cycles at $95^{\circ} \mathrm{C}$ for $10 \mathrm{~s}, 60^{\circ} \mathrm{C}$ for $30 \mathrm{~s}$, and $72{ }^{\circ} \mathrm{C}$ for $60 \mathrm{~s}$. For standard curve construction, serial dilutions were prepared from $100 \mathrm{ng}$ to $10 \mathrm{pg}$ of genomic DNA from P. chlamydosporia PC-170 in $50 \mathrm{ng}$ of tomato root DNA. The cycle threshold (CT) values obtained per well 
containing total DNA (root DNA) were correlated with CT values in the standard curve to calculate the quantity of fungal DNA vs. total DNA.

\subsubsection{PC-170 and Meloidogyne incognita Interact in Tomatoes}

After growing in nutrition bowls for 3 weeks, tomato seedlings with uniform growth were planted in $785 \mathrm{~mL}$ pots, each containing $50 \mathrm{~g}$ of soil (sterilized). Nematode inoculation was performed on the 10th day after PC-170 inoculation. In all experiments, each tomato seedling was uniformly inoculated with $1000 \mathrm{~J} 2 \mathrm{~s}$ in the soil.

\subsubsection{Direct Interaction}

Four main treatment methods were included: (1) without any treatment (CK); (2) inoculation with strain PC-170 (PC); (3) inoculation with M. incognita J2s (M); and (4) inoculation with PC-170 first, and then with M. incognita J2s (PC+M). The tomato variety used in the experiment was Lichun. All plants were placed randomly, with 30 plants per treatment. Three tomato plants were randomly selected and their roots were washed for observation. The fresh weight of shoots (FWS), dry weight of shoots (DWS), fresh weight of roots (FWR), and dry weight of roots (DWR) of the plant were measured after $45 \mathrm{~d}$. The severity of nematode infection of the plants was determined at the same time. Root systems were carefully washed with tap water. Nematode performance was analyzed by counting gall numbers on roots at each timepoint, by visual inspection. Fecundity was determined by counting the number of egg masses and the number of eggs per egg mass after 45 days. The number of egg masses was analyzed by visual inspection, and the percentage of galls showing egg masses was calculated. The number of eggs per egg mass was determined by selecting 10 egg masses randomly from each root system and soaking them in $1 \%$ bleach solution for $5 \mathrm{~min}$. Then, the suspension of eggs was sieved using a $20 \mu \mathrm{m}$ sieve. Released eggs were collected in $5 \mathrm{~mL}$ of water, and the number of eggs was counted with the aid of an Olympus BX51 optical microscope (Olympus Corporation, Tokyo, Japan).

\subsubsection{Split-Root Experiments}

The roots of tomato seedlings were evenly transplanted into two adjacent nutrient bowls, each of which was filled with soil mixed with $20 \mathrm{~mL}$ of PC-170 spore liquid. The split-root experiments consisted of five main treatments: (1) the left and right root systems were not treated $(\mathrm{O}-\mathrm{O})$; (2) the left was pre-inoculated with PC-170, but the right was not treated (PC-O); (3) the left was challenged with $M$. incognita and the right was not treated (M-O); (4) the left was pre-inoculated with PC-170 and challenged with $M$. incognita $(\mathrm{PC}+\mathrm{M}-\mathrm{O})$; and (5) the left was pre-inoculated with $\mathrm{PC}-170$ and the right was challenged with $M$. incognita (PC-M). The tomato variety used in the experiment was Lichun. All plants were placed in a completely random design, with 30 plants per treatment. Plant height and root and shoot weight were measured after 45 days. At the same time, the severity of nematode infection of plants was determined via the methods described above. Among them, treatments (3) and (5) were observed at 15 days, 25 days, and 35 days. At six points in time ( 0 days, 5 days, and 10 days with PC-170, and 1 day, 15 days, and 45 days with $M$. incognita), root material was collected from tomato plants that underwent treatments (3) and (5), and then stored at $-80^{\circ} \mathrm{C}$.

\subsubsection{Mutant Tomato Lines}

The split-root experiments described above were used for all mutant tomato lines. Then, we treated the def1 mutant tomatoes with $20 \mathrm{~mL}$ of $0.1 \mathrm{mM}$ methyl jasmonate (MeJA) solution. MeJA solution was prepared from a $100 \mathrm{mM}$ MeJA (Sigma Odridge (Shanghai) Trading Co., Ltd., Shanghai, China) stock solution in $96 \%$ (v/v) ethanol. The experiment consisted of three main treatments: (1) half of the root system was challenged with $M$. incognita; (2) the left was pre-inoculated with PC-170 and the right was challenged with $M$. incognita; and (3) the left was pre-inoculated with PC-170 and treated with MeJA, while the right was challenged with $M$. incognita. All plants were placed in a completely random 
design, with 30 plants per treatment and three biological replicates for each treatment. At $1 \mathrm{~h}, 6 \mathrm{~h}, 12 \mathrm{~h}, 24 \mathrm{~h}$, and $48 \mathrm{~h}$ after the first treatment with MeJA, and on the 10th day, the colonization of PC-170 in the roots was tested using the method described above. At $45 \mathrm{~d}$, the severity of nematode infection of plants was determined via the methods described above.

\subsubsection{PC-170 and Pathogens Interact in Tomatoes}

Tomato fusarium wilt was grown on PDA plates with rifampicin. After a few days, it was inoculated in potato dextrose broth (PDB) medium and placed on a $28^{\circ} \mathrm{C}$ shaker at 150 revolutions per minute $(\mathrm{rpm})$ to collect spores. The spores were counted using a blood cell counter, and were then diluted to a final density of $1 \times 10^{6}$ spores. $\mathrm{mL}^{-1}$ for use. Using the method of root irrigation, $15 \mathrm{~mL}$ of the spore solution prepared above was added to each tomato root. Tomato bacterial wilt was taken out of sterile distilled water, and then grown on TTC plates (2,3,5-triphenyltetrazoliumchloride, $0.005 \% \mathrm{v} / \mathrm{v})$ for $36 \mathrm{~h}$. Toxic colonies were transferred to the basic medium, and then sterile distilled water was added to prepare an inoculation suspension with a bacterial concentration of about $1 \times 10^{6} \mathrm{cfu} \mathrm{mL}^{-1}$ after expanding for 36-48 h. Cucumber mosaic virus (CMV) and tomato mosaic virus (ToMV) were inoculated by weighing $2 \mathrm{~g}$ of diseased leaves and then adding $10 \mathrm{~mL}$ of phosphate buffer to grind them thoroughly, and were then coated on the surface of tomato leaves that were lightly dusted with carborundum. The experiments were all carried out on Lichun tomatoes. Treatment was carried out on the 10th day after PC-170 inoculation. Each pathogen included two treatments: (1) Only pathogens were inoculated; (2) PC-170 was inoculated in advance before pathogens were inoculated. All plants were placed in a completely random design, with 30 plants per treatment. The test was repeated at least three times, and a consistent trend was obtained. The leaves of three plants were randomly collected and stored at $-80^{\circ} \mathrm{C}$. Disease assessments of CMV and ToMV were conducted throughout the experiment. Specific disease severity ratings were carried out at $10 \mathrm{~d}$ and $20 \mathrm{~d}$. Disease severity was measured according to previous research [45]. Disease severity was measured using a $0-10$ rating scale: $0=$ no symptoms, $2=$ mild mosaic symptoms on leaves, $4=$ severe mosaic symptoms on leaves, $6=$ mosaic symptoms and deformation of leaves, $8=$ severe mosaic symptoms and severe deformation of leaves, and $10=$ severe mosaic symptoms and deformation of leaves with stunted growth. Disease assessments of TFW were carried out at 5 and 10 days. A $0-4$ disease severity scale was classified as follows: $0=$ No infection, $1=$ slight infection, $25 \%$ of full scale-one or two leaves became yellow; 2 = moderate infection-two or three leaves became yellow, 50\% of leaves wilted; 3 = extensive infection-all plant leaves became yellow, $75 \%$ of leaves wilted, and growth was inhibited; 4 = complete infection—all plant leaves became yellow, $100 \%$ of leaves wilted, and the plant died [46]. The disease development of tomato bacterial wilt - expressed as disease incidence (DI) based on a disease index (di) on a scale of 0-4, where $0=$ no wilting, $1=1-25 \%$ wilting; $2=26-50 \%$ wilting, $3=51-75 \%$ wilting, and $4=76-100 \%$ wilted or dead-was recorded 10 and 21 days after challenge [47]. Three replications were maintained for each treatment for the disease incidence study. Disease incidence includes both disease percentage and disease severity, as represented below:

Disease incidence formula:

$$
\text { DI }(\%)=\frac{\sum \text { scale } \times \text { Numbers of infected plants }}{\text { highest scale } \times \text { Total numbers of plants }} \times 100
$$

\subsubsection{Quantitative RT-PCR Analysis}

To analyze the changes in the tomatoes' SA and JA pathways as a result of the fungiplant-nematode interaction, we examined the marker genes involved in the SA and JA pathways. In the SA pathway, the expression of the genes PR-P6, PR1a, PAL and NPR1 was detected. The tomato pathogenesis-related protein $(P R-P 6)$ gene is a pathogenesis-related protein induced by SA, and a direct indicator of the SA response. The gene coding for pathogenesis-related protein (PR1a) is a common marker of SA-regulated responses [48]. 
Phenylalanine ammonia lyase $(P A L)$ is the first enzyme in the phenylpropanoid metabolism pathway. Non-expressor of pathogen-related genes 1 (NPR1) was shown to be a key regulator of SA-mediated suppression of JA signaling [49]. Regarding the JA pathway, the genes PI II, MC, LoxD, and OPR3 were detected. Genes encoding proteinase inhibitor II (PI II) and multicystatin $(M C)$ are the typical JA marker genes [49,50]. LoxD (lipoxygenase $D$ ) is involved in the early steps of the JA pathway, while OPR3 (12-oxophytodienoate 3 reductase) is a JA biosynthesis gene [22,48]. Primers described in Supplementary Table $\mathrm{S} 1$ were used to amplify the targets. We took $10 \mathrm{~g}$ of the roots collected in the above experiment to extract total RNA, and then inverted them into first-strand cDNA. Gene expression was analyzed by qPCR.

Total DNA was extracted using the Plant Genomic DNA Kit (TIANGEN BIOTECH (BEIJING) CO., Ltd.), while total RNA was extracted using the RNAprep Pure Plant Kit (TIANGEN BIOTECH (BEIJING) CO., Ltd.), according to the manufacturer's instructions. First-strand cDNA was synthesized from 1 ug of total RNA using the FastKing gDNA Dispelling RT SuperMix (TIANGEN BIOTECH (BEIJING) CO., Ltd.). Real-time quantitative RT-PCR (qPCR) reactions and relative quantification of specific mRNA levels were performed using the Talent qPCR PreMix (SYBR Green) (TIANGEN BIOTECH (BEIJING) CO., Ltd.) according to the manufacturer's instructions. Reactions were performed in triplicate in a Thermal Cycling StepOnePlus using the following profile: $95^{\circ} \mathrm{C}$ for $15 \mathrm{~min}$, 40 cycles at $95^{\circ} \mathrm{C}$ for $10 \mathrm{~s}, 60^{\circ} \mathrm{C}$ for $30 \mathrm{~s}$ and $72{ }^{\circ} \mathrm{C}$ for $60 \mathrm{~s}$. The gene-specific primers are described in Table S1. Three technical replicas were analyzed. The data were normalized using the housekeeping gene SIEF (X14449), and then the relative expression levels were calculated using the $2^{-\Delta \Delta C T}$ method.

\subsubsection{Statistical Analysis}

All data were subjected to analysis of variance (ANOVA) using SPSS software (IBM, Chicago, IL, USA) to determine significant differences $(p<0.05)$ between treatments. When the data met the normal distribution and the variance was homogeneous, a paired comparison using Student's $t$-test was carried out, or means were compared using Tukey's test $(p<0.05)$. When ANOVA assumptions were not met, multiple comparisons were conducted using the Kruskal-Wallis test, and groups separated by Dunnett's test $(p \leq 0.05)$. All of the experiments were repeated at least three times, with similar results.

\section{Result}

\subsection{Pochonia chlamydosporia PC-170 Colonizes Tomato Roots and Promotes Growth}

It has been reported that $P$. chlamydosporia colonizes plant roots and promotes plant growth. In order to explore the effect of the P. chlamydosporia strain PC-170 on tomato growth, we first studied the effects of different methods used to inoculate tomato roots with PC-170. In the experiment involving the colony inoculation method, within 10 days after the inoculation of the PC-170gfp strain, no endogenous colonized hyphae were detected. In the spore liquid inoculation experiment, we observed the endogrowth of hyphae from the third day, and this phenomenon was first observed in treatment (3) (spore concentration of $5 \times 10^{10}$ spores $\mathrm{mL}^{-1}$ ) with the highest concentration. The growth of tomato plants was observed and compared with the untreated natural growth control group; when the concentration of spore solution was $5 \times 10^{6}$ spores $\cdot \mathrm{mL}^{-1}$, the growth of tomato plants was significantly promoted, while at high concentrations (spore concentration of $5 \times 10^{10}$ spores $\cdot \mathrm{mL}^{-1}$ ) tomato growth was inhibited (Figure 1A). 
A
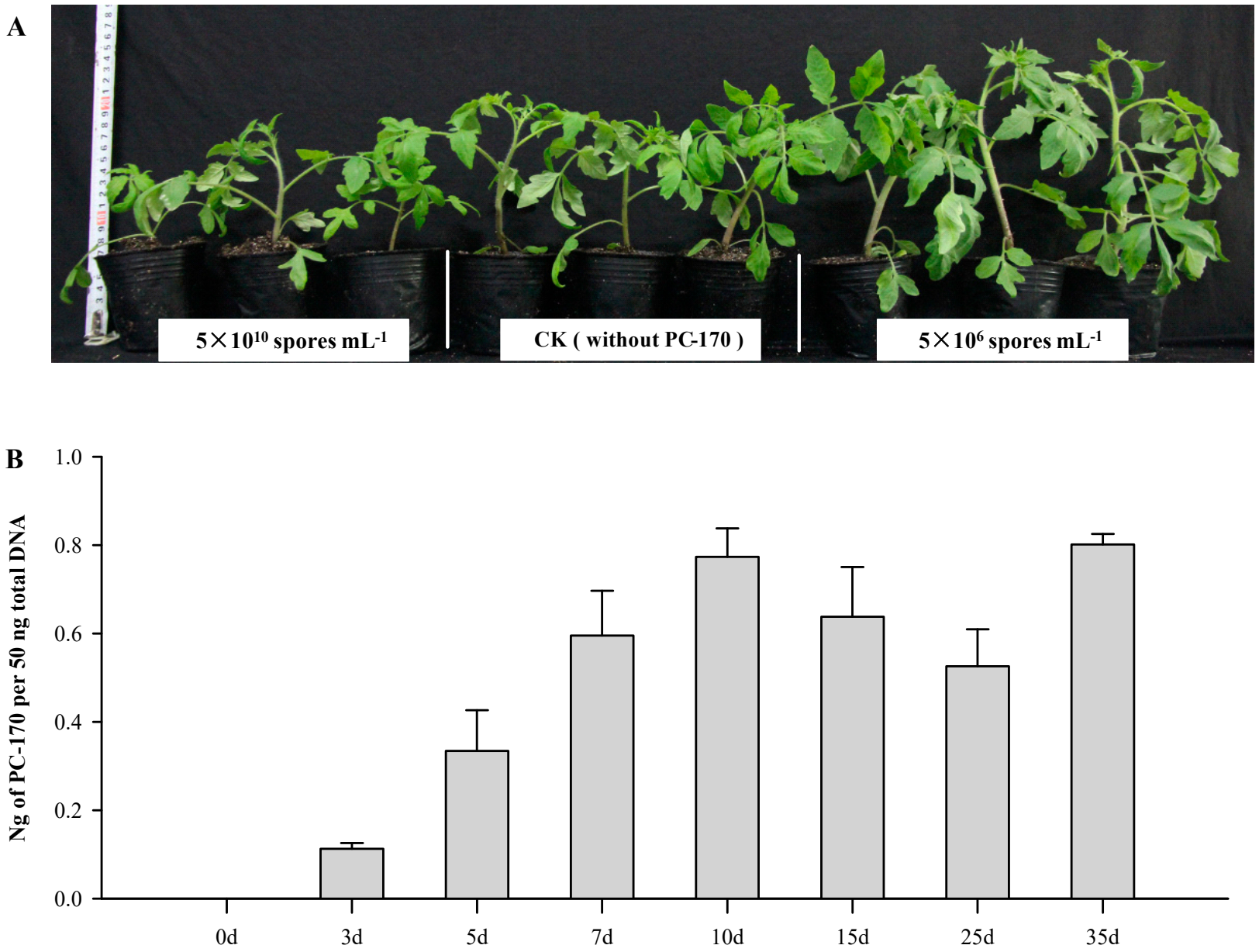

Figure 1. Pochonia chlamydosporia PC-170 colonizes tomato roots. (A) Tomato growth under different PC-170 spore concentrations. (B) The root colonization is expressed as the ratio of fungal DNA biomass per 50 ng of total root DNA. Each value is the mean $\pm \mathrm{SE}$ of three biological samples with three technical replicates each.

In order to determine the colonization process of PC-170 in tomato roots, we measured the total root colonization by $P$. chlamydosporia at different timepoints during treatment (2). The concentration of PC-170 in the roots increased over time, but eventually reached a state of equilibrium (Figure 1B). Therefore, the inoculation concentration of the spore liquid in the subsequent experiments was $5 \times 10^{6}$ spores $\cdot \mathrm{mL}^{-1}$, and other treatments were performed 10 days after inoculation (dai) with PC-170.

\subsection{PC-170 Improves Resistance to Meloidogyne incognita}

In the direct interaction experiment with PC-170, tomato, and root-knot nematodes, we observed that tomatoes inoculated with PC-170 grew faster and had more developed root systems than those not inoculated with PC-170. Second, all Meloidogyne incognita-infected tomatoes exhibited visibly restricted growth; however, this phenomenon was alleviated in plants pre-inoculated with PC-170 (Figure 2A). Additionally, the heights of tomato plants treated with PC-170 were significantly greater than those of the control group of untreated tomatoes; the difference could be observed at 25 dai and 45 dai (Figure 2B). Similarly, fresh root weight (FRW), dry root weight (DRW), fresh shoot weight (FSW), and dry shoot weight (DSW) were also significantly higher in pre-inoculated tomatoes than in the control group (Figure $2 \mathrm{C}$ ). 


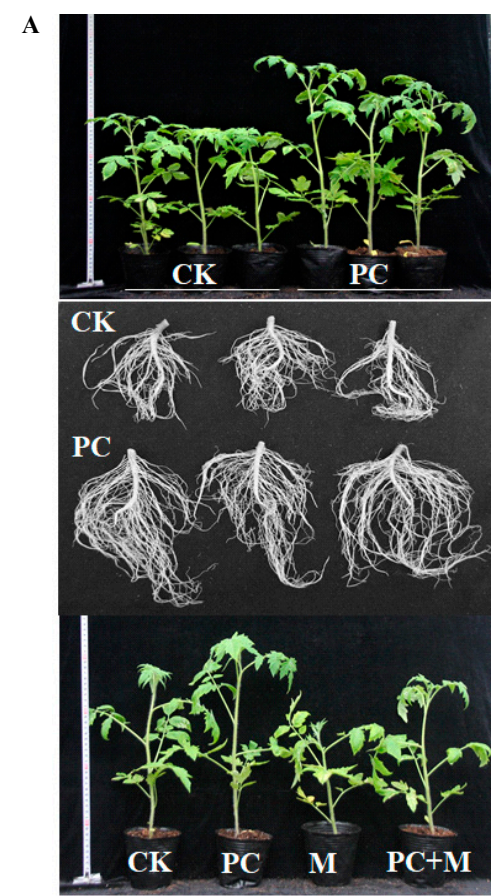

D

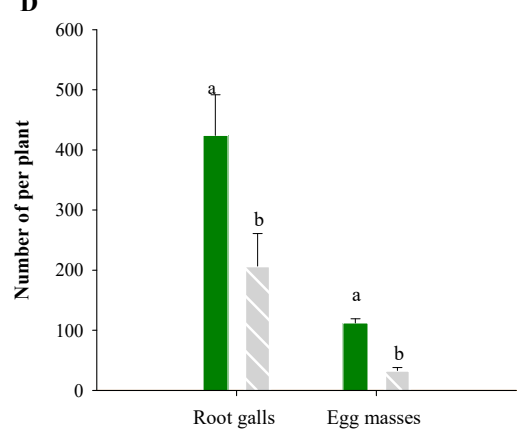

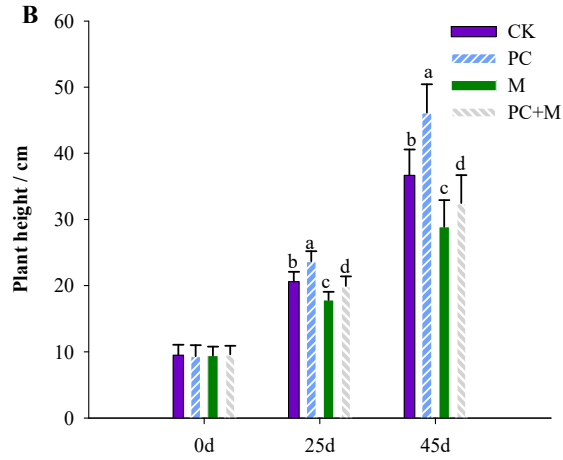

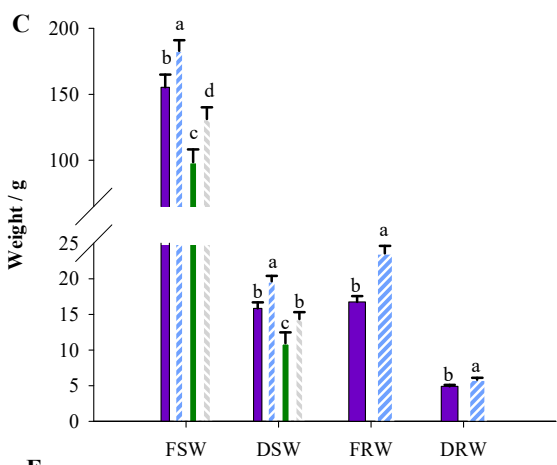

$\mathbf{E}$

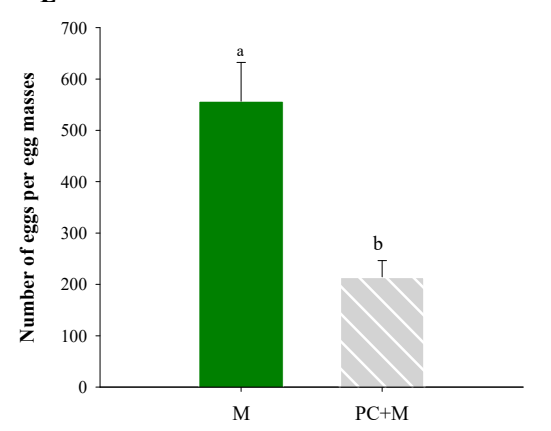

Figure 2. Pochonia chlamydosporia stimulates growth of tomato seedlings and reduces Meloidogyne incognita infection. CK: without any treatment; PC: inoculation with PC-170 strain; M: inoculation with M. incognita J2s; PC+M: inoculate first with PC-170, and then with M. incognita J2s. (A) Root growth $20 \mathrm{~d}$ after inoculation with PC-170. (B) Plant height at $0 \mathrm{~d}, 25 \mathrm{~d}$, and $45 \mathrm{~d}$ under different treatments. (C) FSW (fresh shoot weight), DSW (dry shoot weight), FRW (fresh root weight), and DRW (dry root weight). (D) The number of root galls and the number of egg masses. (E) The number of eggs per egg mass. Each value is the mean \pm SE $(n=30)$. Different letters indicate statistical differences between treatments $(p<0.05)$.

We studied the control effect of the PC-170 strain on M. incognita -infected tomatoes. Compared with plants not inoculated with PC-170, the number of galls on the roots of plants pre-inoculated with PC-170 was reduced by $51.2 \%$, and the average number of egg masses was reduced by $70.0 \%$, while the number of eggs per egg mass was reduced by $58 \%$ (Figure 2D,E).

\subsection{PC-170 Improves Resistance to Different Pathogens in Tomatoes}

Furthermore, we studied the resistance induced by PC-170 in tomatoes to different plant pathogens. Susceptible tomato plants showed symptoms within 10 or 20 dai with pathogens. At 10 days after inoculation with TFW, $16.8 \%$ of tomato plants in the control group showed severe symptoms, while only $3.3 \%$ of PC-170-pre-inoculated plants showed severe symptoms; tomatoes' resistance to TFW was increased by $28.7 \%$ through the action of PC-170 (Figure 3A); therefore, PC-170 played a positive role. However, PC-170 did not show a significant effect on tomatoes inoculated with tomato bacterial wilt (TBW), where 
there was no significant difference between the two treatments. Judging from the disease index, pre-inoculation with PC-170 did not reduce the incidence of TBW (Figure 3B). In the ToMV experiment, we observed similar results. Twenty days after viral inoculation, in the control group, $33.3 \%$ of plants exhibited severe symptoms, $56.7 \%$ of plants exhibited moderate symptoms, and $10.0 \%$ of plants showed weak symptoms. However, in the PC-170-pre-inoculated group, $10.0 \%$ of plants had severe symptoms, $66.6 \%$ of plants had moderate symptoms, and $23.3 \%$ plants showed weak symptoms; tomatoes' resistance to ToMV was increased $40.0 \%$ by PC-170 (Figure 3C). Obvious viral symptoms were observed in $46.7 \%$ of tomato plants not inoculated with PC-170 at 10 dai with CMV, while only $13.3 \%$ of plants pre-inoculated with PC-170 showed obvious viral symptoms. After $20 \mathrm{~d}, 36.7 \%$ of the non-inoculated plants exhibited severe symptoms, with moderate symptoms in $63.3 \%$. In the PC-170-pre-inoculated group, $13.3 \%$ of plants exhibited severe symptoms, $76.7 \%$ of plants displayed moderate symptoms, and $10 \%$ of the plants showed weak symptoms. Inoculation with PC-170 resulted in a $22.2 \%$ increase in tomatoes' resistance to CMV (Figure 3D).
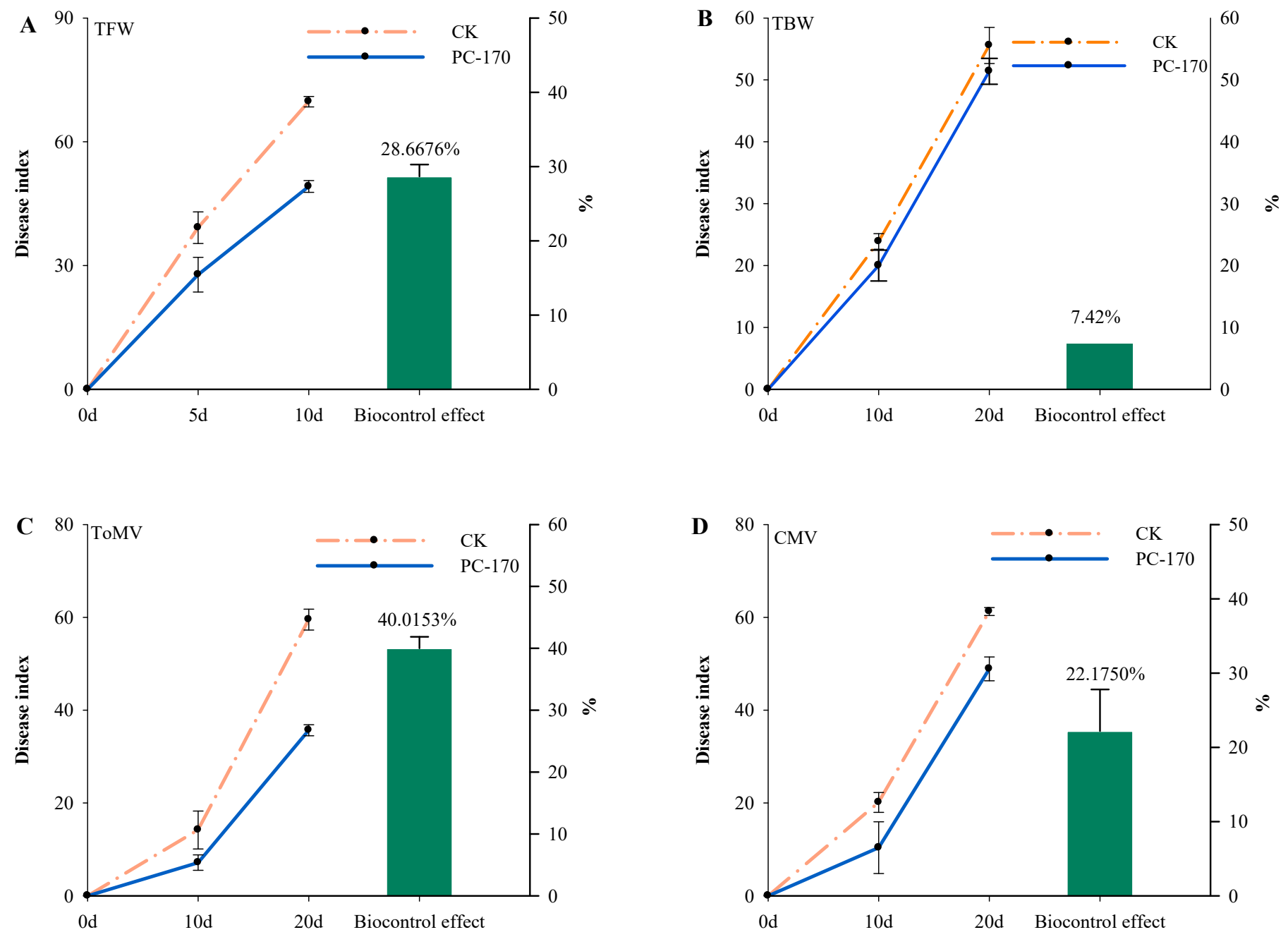

Figure 3. Pochonia chlamydosporia increases tomatoes' resistance to different plant pathogens. (A) Percentage disease level at $5 \mathrm{~d}$ and $10 \mathrm{~d}$, and biocontrol effect, after tomato fusarium wilt (Fusarium oxysporum f. sp. Lycopersici (Sacc.) Snyder and Hansen; TFW) inoculation. (B) Percentage disease level at $10 \mathrm{~d}$ and $20 \mathrm{~d}$, and biocontrol effect, after tomato bacterial wilt (Ralstonia solanacearum (Smith) Yabuuchi et al.; TBW) inoculation. (C) Percentage disease level at $10 \mathrm{~d}$ and $20 \mathrm{~d}$, and biocontrol effect, after tomato mosaic virus (ToMV) inoculation. (D) Percentage disease level at $10 \mathrm{~d}$ and $20 \mathrm{~d}$, and biocontrol effect, after cucumber mosaic virus (CMV) inoculation. Three replications were maintained for each treatment for disease incidence study. 


\subsection{PC-170 Induces Systemic Resistance in Tomatoes}

To study the systemic resistance induced by P. chlamydosporia isolate PC-170 in tomatoes, split-root experiments were conducted. In the split-root experiments, the growth of the plant was observed as in the previous experiments, and the results showed that PC-170 promoted tomato growth, while root development was not affected by the split-root system (Figure 4A,B). The results showed that tomatoes pre-inoculated with PC-170 exhibited reduced numbers of root galls, egg masses, and eggs per egg mass; taking the treatment group $\mathrm{M}-\mathrm{O}$ as a control, the treatment group $\mathrm{PC}+\mathrm{M}-\mathrm{O}$ showed decreases in these metrics of $45.7 \%, 61 \%$ and $50 \%$, respectively, while for the treatment group PC-M the decrease was $35.3 \%, 50 \%$, and $48 \%$, respectively (Figure $4 \mathrm{C}, \mathrm{D}$ ).
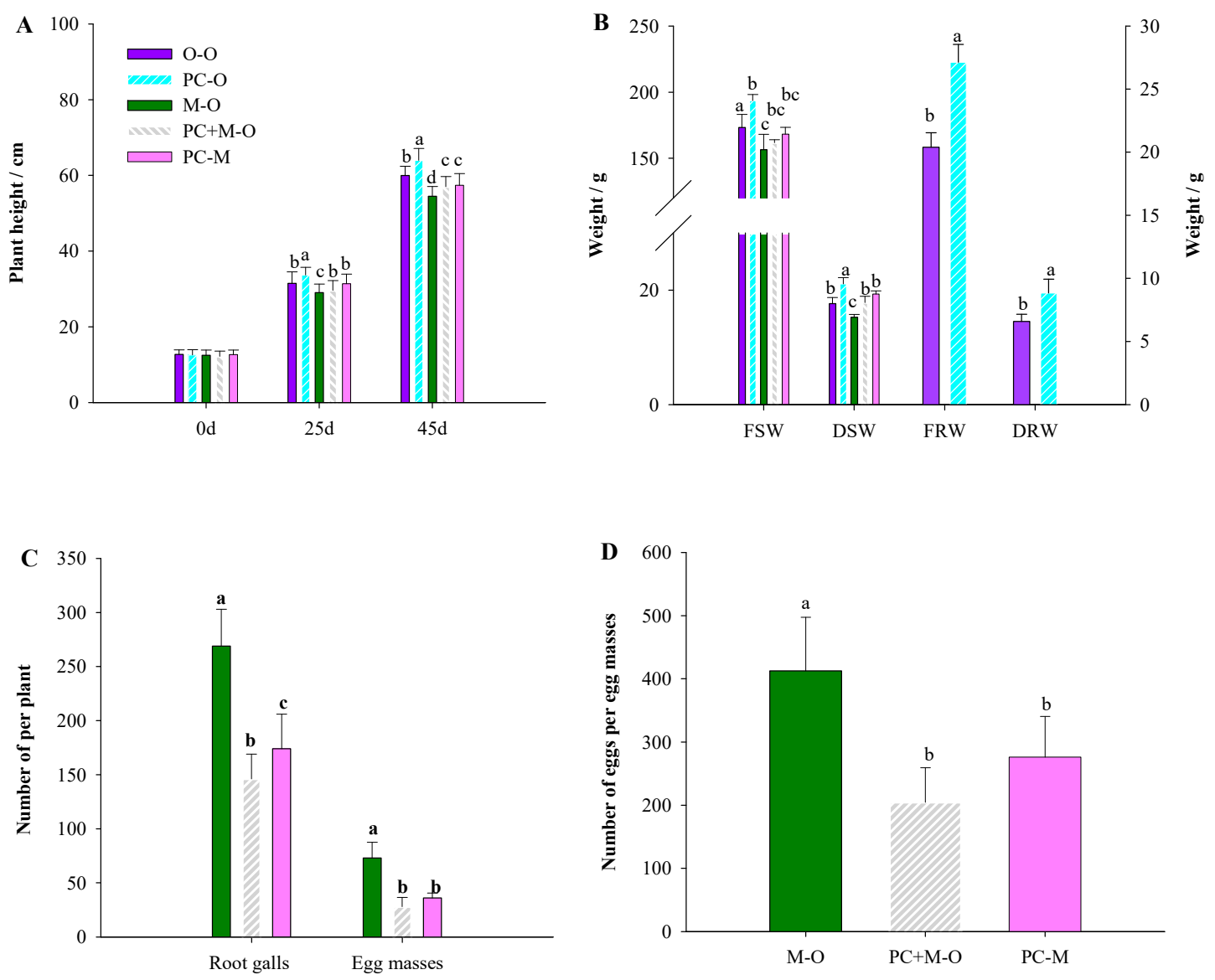

Figure 4. PC-170 improves tomatoes' resistance to Meloidogyne incognita. O-O: The left and right root systems were not treated. PC-O: Just the left root system was pre-inoculated with PC-170. M-O: Just the left root system was challenged with M. incognita. PC+M-O: The left root system was pre-inoculated with PC-170 and challenged with M. incognita. PC-M: The left root system was pre-inoculated with PC-170 while the right was challenged with M. incognita. (A) Plant height at $0 \mathrm{~d}$, $25 \mathrm{~d}$, and $45 \mathrm{~d}$ under different treatments in split-root experiments. (B) Split-root experiments. FSW: fresh shoot weight; DSW: dry shoot weight; FRW: fresh root weight; DRW: dry root weight. (C) In the split-root experiment, the number of root galls and the number of egg masses. (D) In the split-root experiment, the number of eggs per egg mass. Each value is the mean \pm SE $(n=30)$. Different letters indicate statistical differences between treatments $(p<0.05)$.

The effect of PC-170 on the reproduction of $M$. incognita in tomato roots was investigated at 15, 25, 35, and 45 dai. From 15 to 45 dai, a significant reduction in the number of root galls was observed in the roots of plants treated with PC-170; no egg masses were observed at 15 dai, and there was a significant reduction in the number of egg masses in the plants pre-inoculated with PC-170 at 25 and 45 dai (Figure 5). 


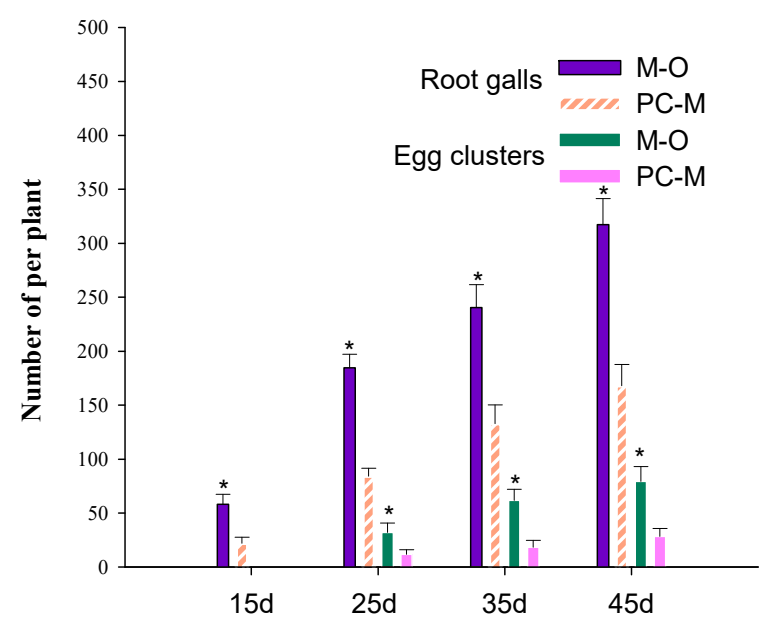

Figure 5. Comparison between the two treatments. M-O: Just the left root system was challenged with Meloidogyne incognita. PC-M: The left root system was pre-inoculated with PC-170, while the right was challenged with $M$. incognita. Each value is the mean $\pm \mathrm{SE}(n=10)$. ${ }^{*}$ indicates statistical differences between treatments $(p<0.05)$.

\subsection{Expression of Defense Pathway Marker Genes in Different Interactions}

Before inoculation with Meloidogyne incognita, we observed that in the SA pathway, compared with the plants not inoculated with PC-170, the expression of the PAL gene in the plants inoculated with PC-170 did not increase significantly (Figure 6A). The expression of the NPR1 gene was increased significantly at 5 days after inoculation with PC-170 (daip) (Figure 6B). Similarly, the expression of the PR1 $a$ and PR-P6 genes did not change significantly (Figure 6C,D). However, in the JA pathway, the expression levels of the LoxD and OPR3 genes increased significantly at at 5 daip and 10 daip (Figure 6E,F). Compared with the levels of genes at 5 daip, the amount of expression was lower again at 10 daip. High expression levels of the induced genes PI II and MC were also observed at 5 daip and 10 daip. It can be seen that the colonization of PC-170 activated the JA pathway (Figure 6G,H).

After inoculation with Meloidogyne incognita, we observed the expression of each gene in the plants of the $\mathrm{M}-\mathrm{O}$ treatment group, and found that the expression level of the PAL gene increased significantly at 1 days after inoculation with Meloidogyne incognita (daim). Compared with the expression level at 1 daim, the expression level decreased at 15 daim, then increased again at 30 daim, and decreased once more at 45 daim (Figure 6A). The expression trends of the NPR1, PR1a, and PR-P6 genes were also consistent (Figure $6 \mathrm{~B}, \mathrm{C}, \mathrm{D})$. In the JA pathway, the expression of the LoxD and OPR3 genes decreased at 1 daim and 30 daim, and increased at 15 daim and 45 daim (Figure 6E,F). The expression of the inducible genes PI II and MC increased significantly at 15 daim (Figure 6G,H). Therefore, we can conclude that the SA pathway was the first to be activated in nematode infection. The JA pathway was also activated during the development of the nematodes in the roots (15 daim), and then the SA JA pathways appeared alternately during the time period when the nematode infestation returned (30-45 daim).

Taking the M-O treatment group as a control, we can see that after nematode infection, the expression of the SA pathway marker genes increased more significantly in the PC-M treatment. At each stage, the expression was significantly higher than that in the $\mathrm{M}-\mathrm{O}$ treatment group. In the JA pathway, nematode infection caused the expression of marker genes to drop rapidly, but then it increased again at 15 daim. Consistent with the SA approach, the changes in gene expression in the $\mathrm{PC}-\mathrm{M}$ treatment group were significantly greater than in the $\mathrm{M}-\mathrm{O}$ treatment group. Moreover, the gene expression of the JA pathway was not completely suppressed. 

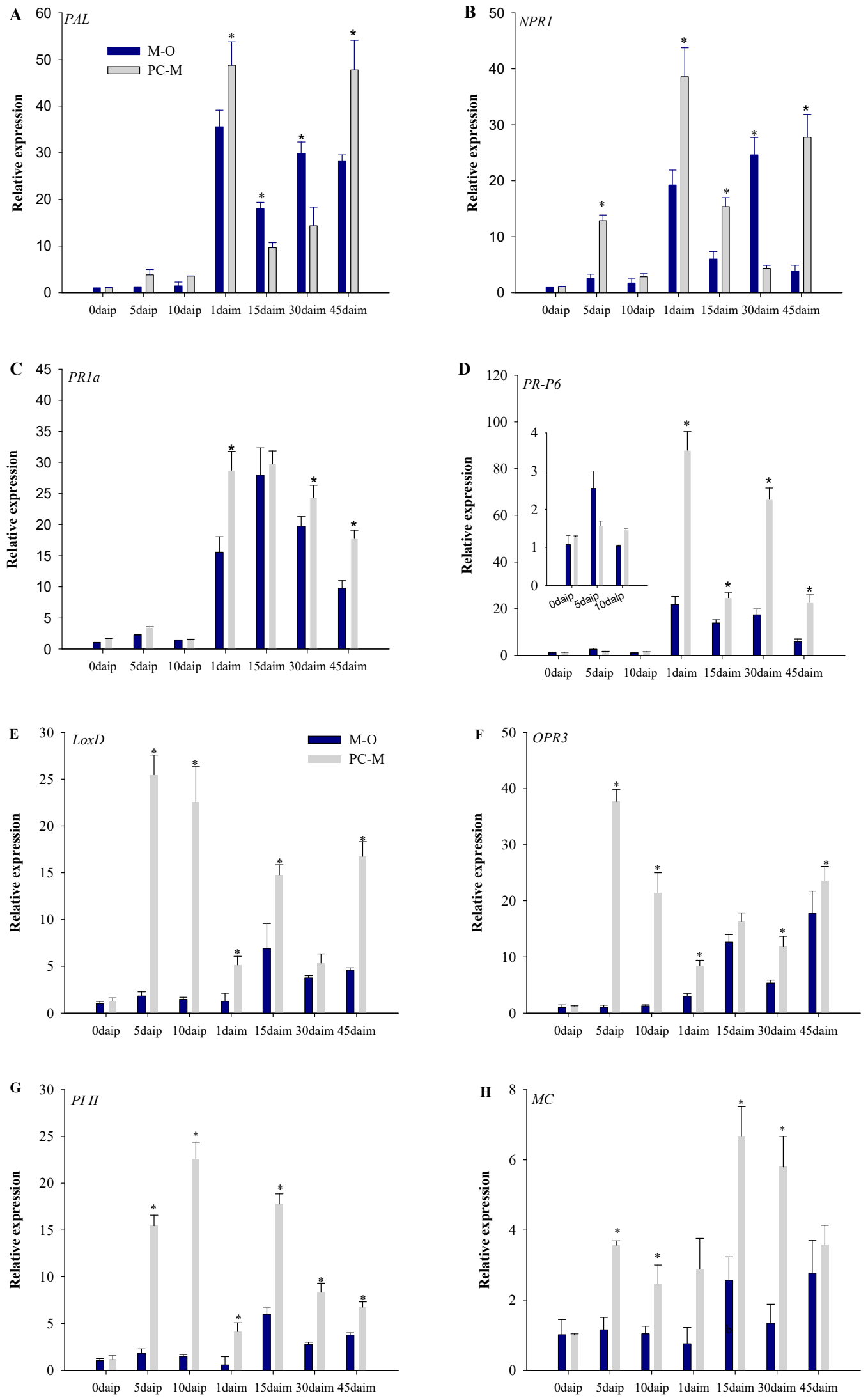

Figure 6. The expression changes of the salicylic acid (SA) marker genes and the jasmonic acid (JA) marker genes. M-O: Just the left root system was challenged with Meloidogyne incognita. PC-M: The left root system was pre-inoculated with PC-170, while the right was challenged with M. incognita. 
daip: days after inoculation with PC-170; daim: days after inoculation with Meloidogyne incognita. (A) The expression of the SA biosynthesis gene PAL. (B) The expression of the SA-dependent, defenserelated gene NPR1. (C) The expression of the SA-responsive marker gene PR1a. (D) The expression of the SA-responsive marker gene PR-P6. (E) The expression of the JA biosynthesis gene LoxD. (F) The expression of the JA biosynthesis gene gene OPR3. (G) The expression of the JA-regulated, wound-related gene PI II. (H) The expression of the JA-regulated, wound-related gene MC. Each value is the mean $\pm \mathrm{SE}$ of three biological samples with three technical replicates each. ${ }^{*}$ indicates statistical differences between treatments $(p<0.05)$.

When PC-170 and plant pathogens interacted in tomatoes, we detected the marker genes involved in the SA and JA pathways. When PC-170 and ToMV interacted in tomatoes, it could be observed that the PR-P6 and PI II genes were activated. In the pre-inoculated PC170 tomato leaves, it was found that the PL-II gene had been activated and expressed. After inoculation with ToMV, the expression of the gene continued to be upregulated; however, the expression of the $P R-P 6$ gene was significantly upregulated at 10 dai, and decreased at 20 dai (Figure 7A). When PC-170 and TFW interacted in tomatoes, the expression of the $P R-P 6$ and PI II genes was activated after inoculation with TFW. In tomatoes pre-inoculated with PC-170, the fold and duration of gene upregulation were enhanced (Figure 7B). In the process of PC-170 and CMV interacting in tomatoes, the PR-P6 and PI II genes were activated. However, the expression of different genes was upregulated at different time periods. It can be seen that the upregulation fold of genes in tomatoes pre-inoculated with PC-170 was significantly higher than that in non-inoculated tomatoes (Figure 7C). When tomatoes were inoculated with TBW, expression of the PR-P6 and PI II genes was activated. The expression of the $P R-P 6$ gene was significantly upregulated, while the expression of the PI II gene was first upregulated and then downregulated. In the tomatoes pre-inoculated with PC-170, the gene expression pattern was consistent with that of the control group; however, the gene expression advantage induced by PC-170 was not reflected (Figure 7D).

\subsection{PC-170 and Meloidogyne incognita Interact in Mutant Tomato Lines}

To further analyze the roles of SA and JA signaling in the promotion of growth and protective effects induced by PC-170, nematode infection was assessed in the NahG mutant and in the def1 mutant, as well as their corresponding background wild-type tomato lines. First, we found that not only in the Lichun tomatoes, but also in the Castlemart and Moneymaker tomato varieties, PC-170 showed a growth-promoting effect. Remarkably, the growth-promoting effect was lost in the def1 mutant, and the tomato plants' heights were significantly lower than those of the control group that were not inoculated with PC-170. Similarly, the fresh root weight (FRW), dry root weight (DRW), fresh shoot weight (FSW), and dry shoot weight (DSW) were also significantly lower compared to those in the control group (Table S2).

In the background wild-type tomato lines (Castlemart and Moneymaker), the root galls of plants were reduced by approximately $50 \%$ in the $\mathrm{PC}+\mathrm{M}-\mathrm{O}$ treatment group, and by approximately $40.0 \%$ in the PC $-\mathrm{M}$ treatment group, compared with the control $\mathrm{M}-\mathrm{O}$ treatment group. However, in SA-deficient NahG tomato plants, the root galls of the $\mathrm{PC}+\mathrm{M}-\mathrm{O}$ treatment group were reduced by $24 \%$, while in the $\mathrm{PC}-\mathrm{M}$ treatment group they were reduced by $20 \%$, compared with the control $\mathrm{M}-\mathrm{O}$ treatment group. Compared with the Moneymaker background line, the effect of PC-170 was noticeably limited in the NahG mutant. In the JA-deficient def1 mutant, compared with the control $\mathrm{M}-\mathrm{O}$ treatment group, the root galls of the $\mathrm{PC}+\mathrm{M}-\mathrm{O}$ treatment group were reduced by $16 \%$, while in the $\mathrm{PC}-\mathrm{M}$ treatment group they were reduced by $3 \%$. Compared with the Castlemart background line, the effect of PC-170 was significantly reduced in the def1 mutant. Similarly, statistical analysis of the number of egg clusters per plant found that this systemic protection was reduced in SA-deficient NahG tomato plants. In contrast to $N a h G$ plants, this systemic protection was almost entirely lost in the JA-deficient def1 mutant (Figure 8A,B). 

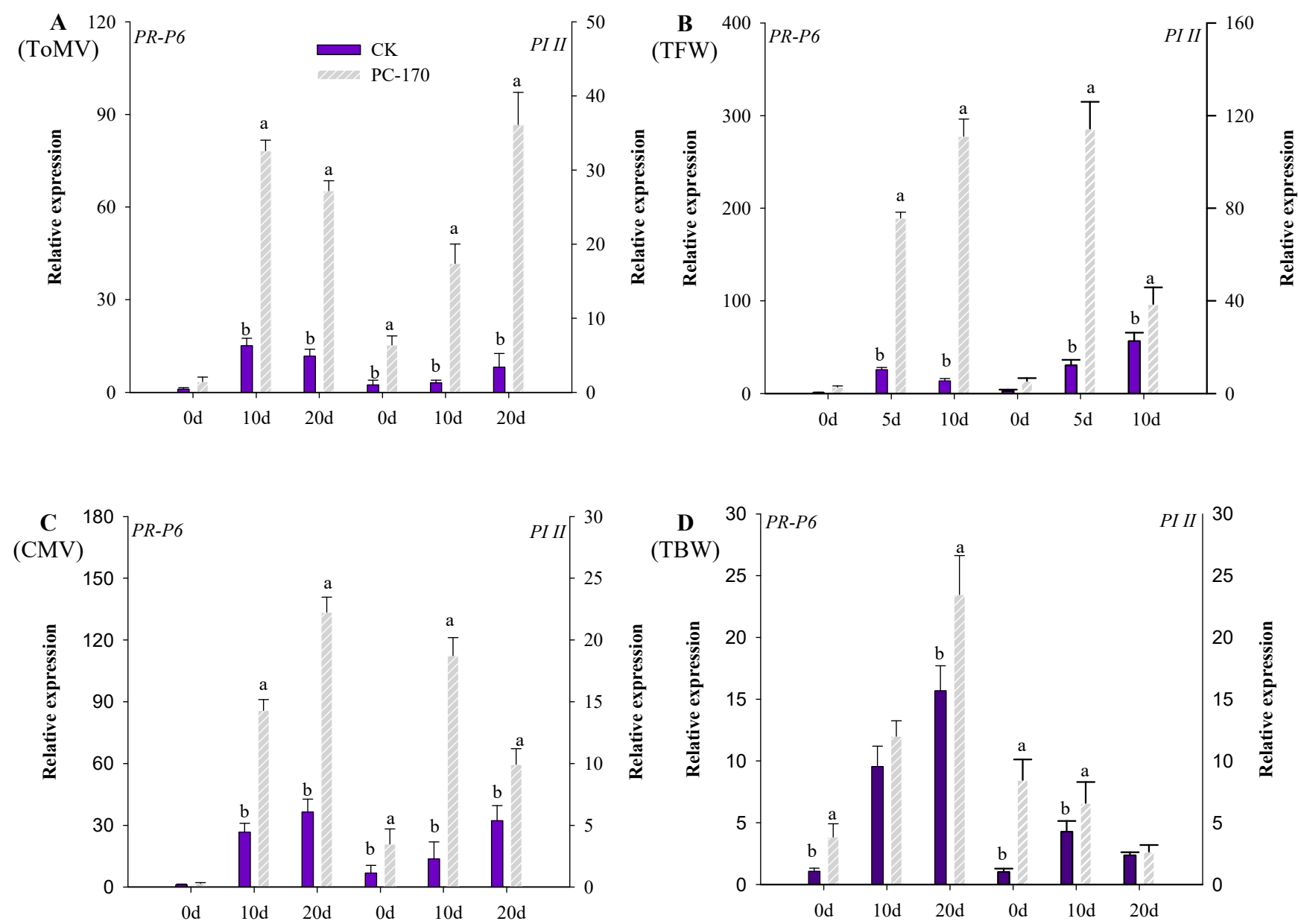

Figure 7. The expression of genes when PC-170 and pathogens interact in tomatoes. (A) The changes in the expression of the PR-P6 and PI II genes during pathogenesis after ToMV inoculation. (B) The changes in the expression of the PR-P6 and PI II genes during pathogenesis after TFW inoculation. (C) The changes in the expression of the PR-P6 and PI II genes during pathogenesis after CMV inoculation. (D) The changes in the expression of the PR-P6 and PI II genes during pathogenesis after TBW inoculation. Each value is the mean \pm SE of three biological samples with three technical replicates each. Different letters indicate statistical differences between treatments $(p<0.05)$.

Next, the ability of PC-170 to activate JA signaling after exogenous hormone application was investigated. Proteinase inhibitor II (PI II) gene expression was induced by exogenously applying methyl jasmonate (MeJA) to the roots. The induction of the PI II gene in plants pre-inoculated with PC-170 was stronger and more durable (Figure 8D). These results suggest that PC-170 primes JA-dependent defense signaling in systemic root tissue, which probably affects the inhibitory effect on JA-mediated signaling by M. incognita. We also treated the JA-deficient def1 mutant with MeJA to investigate whether it could regain induced resistance (Figure $8 \mathrm{C}$ ). The results showed that the JA-deficient def1 mutant could regain resistance to nematode infection in PC-170-pre-inoculated plants as a result of spraying with the exogenous hormone MeJA.

We compared the colonization of PC-170 in the roots under the following different conditions: (1) Castlemart tomatoes inoculated with PC-170; (2) def1 mutant tomatoes inoculated with PC-170; (3) def1 mutant tomatoes inoculated with PC-170 and treated with the exogenous hormone MeJA. We collected roots to detect the total root colonization after 10 days. Compared with the total colonization of PC-170 in Castlemart tomatoes, the total colonization of PC-170 in def1 mutant tomatoes increased significantly. However, the total colonization of PC-170 was reduced when def1 mutant tomatoes were treated with the exogenous hormone MeJA (Figure 9). 

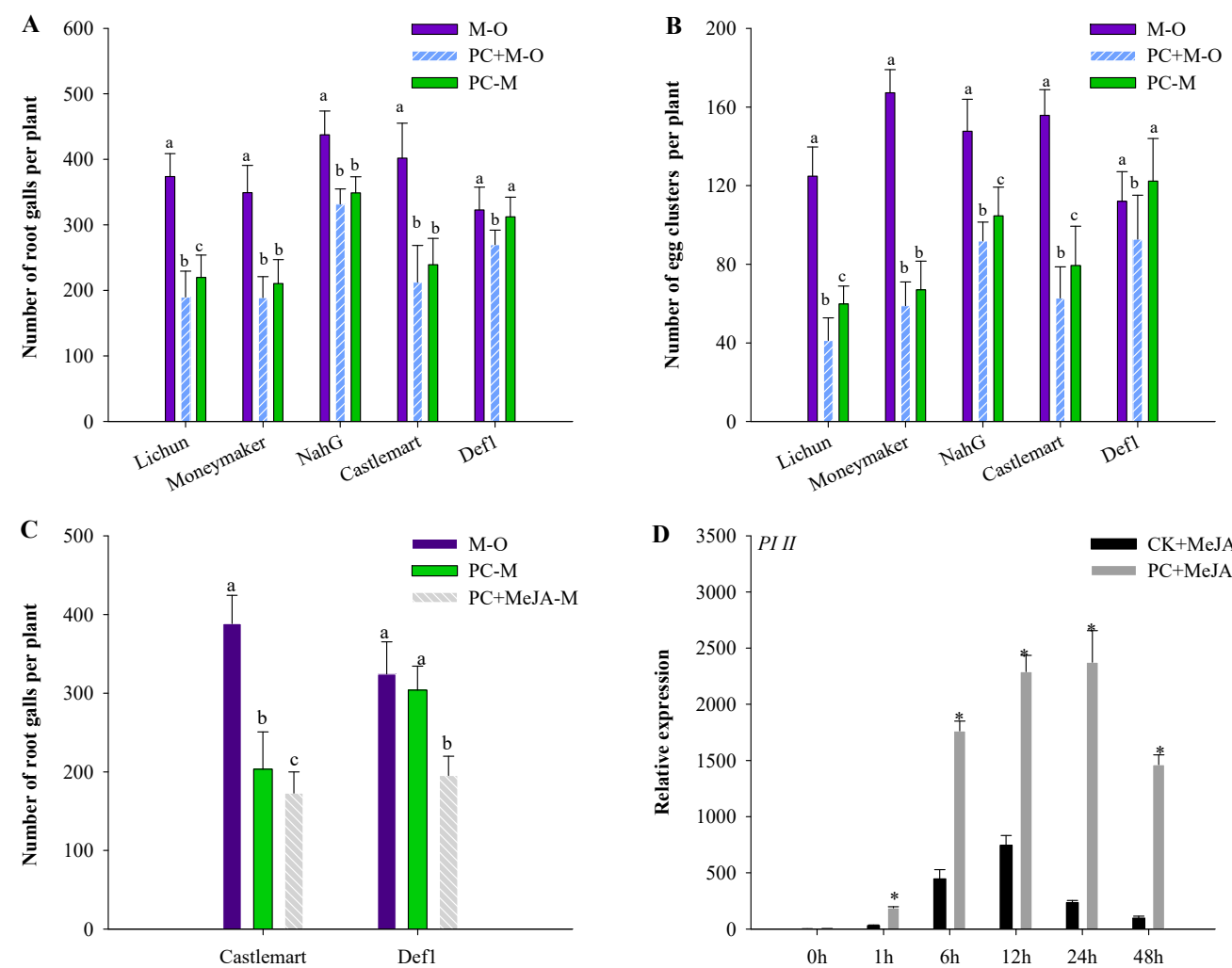

Figure 8. Pochonia chlamydosporia-induced resistance against Meloidogyne incognita in different tomato lines (A) The number of root galls was monitored at $45 \mathrm{~d}$ after inoculation with $M$. incognita. (B) The number of egg clusters in the roots was monitored at $45 \mathrm{~d}$ after inoculation with $M$. incognita. Data are the mean $\pm \mathrm{SE}(n=30)$. (C) The number of galls was monitored at $45 \mathrm{~d}$ after exogenous application of methyl jasmonate (MeJA). Data are the mean $\pm \mathrm{SE}(n=30)$. Each value is the mean \pm SE of three biological samples. Different letters indicate statistical differences between treatments $(p<0.05)$. Each value is the mean \pm SE $(n=30)$. (D) PI II was analyzed at six time points after exogenous application of methyl jasmonate (MeJA). Each value is the mean $\pm \mathrm{SE}$ of three biological samples with three technical replicates each. ${ }^{*}$ indicate a significant difference from non-PC-170-inoculated plants according to Dunnett's test $(p<0.05 ; n=5)$.

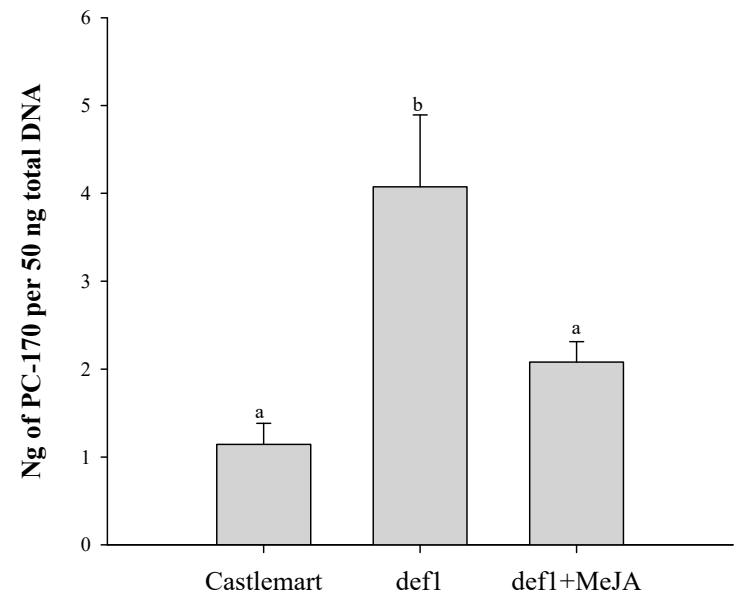

Figure 9. The colonization of PC-170 in the roots under the following different conditions: Castlemart: Castlemart tomatoes inoculated with PC-170; def1: def1 mutant tomatoes inoculated with PC-170; def1+MeJA: def1 mutant tomatoes inoculated with PC-170 and treated with the exogenous hormone MeJA. Each value is the mean $\pm \mathrm{SE}(n=30)$. Different letters indicate statistical differences between treatments $(p<0.05)$. 


\section{Discussion}

Plants, unlike other forms of life, cannot move to escape biotic or abiotic stresses. However, plants have evolved alongside microbes. The plant microbiome is a basic and important partner in protecting the plant from stresses, in that it not only synthesizes enzymes or metabolites and produces important phytohormones that can negatively affect plant pathogens and ensure the tolerance of the plant to environmental stress [51], but also induces systemic resistance in plants by colonizing their roots [52]. These organisms that live in healthy plant tissues but do not cause disease are called endophytes. Most bacterial and fungal endophytes benefit plants by promoting growth or suppressing pathogens, and some can even improve the stress tolerance and immunity of plants [51]. Cooperation between host plants and endophytes is one of the strategies that assist plants in adapting, surviving, and developing.

It has been reported that Pochonia spp. can colonize roots; acting as a root endophyte, their capacity to colonize and proliferate in roots greatly varies between isolates $[22,53,54]$. Studies have shown that $P$. chlamydosporia has multiple functions in promoting plants' growth and increasing their yield or promoting flowering when colonizing their roots [18] Our results indicate that the P. chlamydosporia isolate PC-170 colonizes and proliferates in tomato roots. Isolate PC-170 exerts a positive effect on tomato plant growth by promoting root development and increasing tomato growth under greenhouse conditions. Previous evidence also indicated that endophyte over-colonization could limit plant growth through an excess of nutrients transferred to fungal partners [18]. An effective innate immunity system was exploited to avoid root over-colonization by beneficial endophytes that may affect development $[7,55]$. Immune responses were induced by their progressive reduction at later stages when plants perceive beneficial fungi $[52,56]$. Likewise, we found that the change in JA signaling in PC-170 pre-inoculated plants conforms to this scenario. Our results showed that PC-170 in the root system would not increase after reaching a certain amount, and the gene PL-II was upregulated at 5 and 10 dai with PC-170. Interestingly, when using the PC-170 spore liquid inoculation method, low-concentration spore liquid grows slowly in the soil, but too high a concentration of spore liquid inhibits the growth of tomato plants. We speculate that PC-170 is a dose-dependent beneficial endophyte. In the JA-deficient def1 mutant (Castlemart) tomatoes, the effect of growth promotion by PC-170 was lost. Numerous reports showed that JA signaling was involved in carbohydrate partitioning and limiting colonization $[18,55,57]$. There is also evidence showing that plant defense responses contribute to restricting beneficial endophytic colonization by modulating JA signaling [58]. In tomatoes, JA signaling affects the colonization of mycorrhizal fungi by modifying the expression of some downstream genes involved in carbohydrate partitioning [59]. Our results suggest a role for JA in modulating the colonization of tomatoes by PC-170, and also confirm that adaptive JA signaling is necessary to regulate PC-170 colonization and its benefits. Thus, in the JA-deficient def1 mutant (Castlemart) tomato plants, the colonization of PC-170 was not effectively controlled by the plant itself, leading to the inhibition of plant growth. Studies have shown that the colonization of $P$. chlamydosporia on barley roots can upregulate phytohormone-synthesis-related genes, such as auxin, ethylene, and jasmonic-acid-synthesis-related genes [7]. It is very possible that, in this interaction, auxin-synthesis-related genes are also upregulated so that PC-170 can exert a growth-promoting effect; this point requires further confirmation.

$P$. chlamydosporia, which is a nematode egg parasitoid fungus with worldwide distribution, has been applied to the biological control of nematodes in many economically important crops $[9,12-15]$. The study of P. chlamydosporia in lettuce, cucumbers, tomatoes, and bananas also revealed that it can reduce the infection rate of nematodes [60]. In this study, PC-170 increased tomatoes' resistance to root-knot nematodes by reducing the number of root galls and egg masses per plant. PC-170 not only affects infection by nematodes, but also affects the reproduction of nematodes within the roots. We also found that PC-170 grants tomato plants advantages, including helping them to mitigate growth inhibition by nematodes. Thus, PC-170 can be used as a biological control agent to control nematodes. 
Many studies have proven that endophytic fungi are able to protect plants against a range of soil-borne pathogens. In studies of root endophytism, researchers found that a large proportion of fungal root endophytes are antagonistic to important root pathogens such as wilt and take-all fungi [61]. P. chlamydosporia plays an active role in suppressing plant pathogens. For example, colonization by P. chlamydosporia reduced the occurrence of other fungi in the roots [15]. Some study provides evidence that three nematophagous fungi can also reduce root colonization and root damage by fungal pathogens; P. chlamydosporia was included. In Petri dish experiments, P. chlamydosporia reduced colonization of barley roots by Gaeumannomyces graminis var. tritici (Ggt), and also reduced necrotic symptoms [20]. In our research, we found that PC-170 played a positive role in increasing tomatoes' resistance to TFW. However, PC-170 did not show a significant effect on tomatoes inoculated with tomato bacterial wilt (TBW); judging from the disease index, pre-inoculation with PC-170 did not reduce the incidence of TBW. Therefore, PC-170 cannot play a positive role in the fight against all pathogens. In addition to soil-borne pathogens, we also found that PC-170 affects tomatoes' resistance to viral diseases on leaves. CMV disease severity ratings were significantly lower for PC-170-treated tomato plants than for control plants at 10 and 20 dai. In the ToMV experiment, we also observed similar results. Moreover, we found that a delayed onset time can be observed when PC-170 interacts with pathogens in tomatoes. The results show that the colonization of tomato roots by PC-170 can induce systemic protection against foliar pathogens.

Trichoderma atroviride (Ta) significantly reduces the number of galls and adult nematodes inside tomato roots. Ta induces systemic resistance against Meloidogyne javanica (Mj), as demonstrated by an in vivo split-root experiment, without the need for the organisms to be in direct contact [36]. In order to prove the defensive mechanism of P. chlamydosporia in the fungus-plant interaction, study of split-root experiments demonstrates that the differential $P$. chlamydosporia isolates induce systemic resistance against $M$. incognita in tomatoes, but not in cucumber; thus, whether P. chlamydosporia can induce systemic resistance against root-knot nematodes depends on the plant species [22]. We also observed that plant-mediated resistance induced by P. chlamydosporia impacted the nematode parasitism in the split-root experiments, in a manner distinct from the possible direct nematicidal effects of the PC-170 fungus [62]. P. chlamydosporia induced plant defense mechanisms in fungus-plant interaction studies.

Trichoderma species can protect plants from pathogens or insect attack by inducing defense responses [63]. There are multiple transduction pathways that regulate Trichodermainduced resistance, and the response ability of plants inoculated with Trichoderma species against multiple pathogens was improved by the ability to alternately activate different resistance-regulatory mechanisms [64,65]. Trichoderma priming of SA- and JA-dependent defenses in roots was plastic and adaptive to the parasitism stage. Trichoderma primed SAregulated defenses to limit nematode root invasion, and enhanced JA-regulated defenses, which compromised galling and fecundity [37]. In 2015, researchers found an upregulation of genes implicated in the biosynthesis of plant hormones-such as auxin, ethylene and jasmonic acid-by analyzing the barley root transcriptomic response to P. Chlamydosporia colonization of roots [7]. Study of $P$. chlamydosporia-induced plant resistance by the splitroot method revealed that the expression of the salicylic acid pathway (PR-1 gene) and the jasmonate signaling pathway (Lox D gene) in tomato roots was induced both after being inoculated with the fungal isolate and after nematode inoculation [22]. In this study, we found that the relevant marker genes of the jasmonate signaling pathway were the first to be activated. As mentioned above, the JA pathway was involved in the regulation of the colonization of P. chlamydosporia; after inoculation with nematodes, the relevant marker genes of the SA pathway were activated. We found that the SA and JA pathways exhibited a certain antagonism, but at a certain point in time showed a synergistic effect in the process of resistance to nematodes, by analyzing the expression of related genes of the two pathways at the stage of nematode growth and development, which is a plastic phenomenon similar to that revealed by research on the anti-nematode Trichoderma. During 
the period from the first infestation of nematodes to the occurrence of the second infection, both the SA pathway and the JA pathway are induced and activated. However, the colonization of PC-170 in the roots makes this induction more rapid and intense, so it can increase the resistance of tomatoes to nematodes. Kammerhofer [30] found that jasmonic acid triggers early defense responses against Heterodera schachtii, but during later syncytium and female development, salicylic acid seems to be a negative regulator. In the study of PC170 inducing tomato resistance to pathogens, the activation of defense signaling pathways also occurred. When analyzing the expression of marker genes, it was found that different pathogens activate the SA and JA pathways in different orders, which is related to different pathogens' different mechanisms of action on tomatoes. Among the pathogens to which PC170 plays an active role in resistance, we found that the activation of the signaling pathway became more intense, and the fold and duration of gene upregulation were improved.

We used mutant lines to verify the PC-170-induced resistance in tomatoes. In 2017, Martinez-Medina et al. showed that the systemic protection induced by T. harzianum was still able to protect the roots of the JA-deficient def1 mutant against nematode invasion, but was lost in SA-deficient NahG plants [37]. We used mutant tomato lines to analyze the effects of pathways on PC-170-induced resistance. The difference from T. harzianum was that we found that PC-170-mediated plant resistance against nematode invasion was restricted in NahG plants. Thus, we can conclude that the induction of SA-dependent defenses by PC170 during $M$. incognita infection putatively contributed to plants' resistance to nematodes. However, PC-170-mediated plant resistance to nematode invasion was completely blocked in def1 plants, while the JA-deficient def1 mutant could regain resistance to nematode infection in PC-170-pre-inoculated plants after spraying with the exogenous hormone MeJA; this is in contrast to the results of some other studies [22,37]. The JA pathway seems to play an indispensable role in tomatoes' resistance to nematodes. In the absence of the SA pathway, there may be other hormones or synthetic pathways that can play the same role and act as a substitute for SA. The lack of JA has an impact on plants not only in terms of inducing resistance, but also in terms of growth. It may be precisely because this effect is multifaceted that it highlights the importance of JA to plants. All in all, we can know that both the SA and JA signaling pathways play roles in the process of PC-170-induced resistance to root-knot nematodes in tomatoes. Defense pathways play different roles at different points in time. In the process of PC-170 colonization, the JA pathway plays a role in regulating the colonization. When roots are infested by nematodes, the SA pathway is the first to play a role, while the JA pathway mainly plays a role during the reproduction of the nematode.

\section{Conclusions}

In conclusion, this study confirmed that $P$. chlamydosporia colonizes and proliferates in tomato roots. Isolate PC-170 had a positive effect on tomato growth, promoted root development, and increased tomato growth under greenhouse conditions. PC-170 increased tomatoes' resistance to root-knot nematodes and induced systemic resistance. The JA pathway of plants regulates the colonization of PC-170; then, the JA pathway cooperates with the SA pathway to induce resistance to $M$. incognita and other pathogens in tomatoes. One of the challenges for the future will be the establishment of assays to unravel the regulatory mechanism of endophytes, and to show how PC-170 orchestrates downstream responses during interactions with root cells.

Supplementary Materials: The following are available online at https:/ / www.mdpi.com/article/10.3 390/microorganisms9091882/s1. Table S1. Primer sequences used for real-time qPCR analysis [66-69]. Table S2. The effect of the PC-170 strain of Pochonia chlamydosporia on the growth of different tomato species in two split-root experiments. 
Author Contributions: Conceptualization, G.-S.Y. and B.-Y.X.; data curation, J.-L.Z.; formal analysis, X.Z. and Y.-L.L.; funding acquisition, B.-Y.X.; investigation, X.Z. and M.B.; methodology, G.-S.Y. and B.-Y.X.; project administration, Z.-C.M. and G.-S.Y.; resources, J.-L.Z. and Y.-H.Y.; software, X.-X.P.; supervision, M.B. and B.-Y.X.; visualization, M.B.; writing-original draft, X.Z.; writing-review and editing, X.Z., J.-L.Z. and M.B. All authors have read and agreed to the published version of the manuscript.

Funding: This work was supported by the National Natural Science Foundation of China (32072396), the National Key R \& D Program (2017YFD0200600 and 2016YFD0201000), and the China Agriculture Research System (CARS-25).

Data Availability Statement: The data that supports the findings of this study are available in the supplementary material of this article.

Acknowledgments: A hearty thanks to the Institute of Vegetables and Flowers Chinese Academy of Agricultural Sciences, the Engineering Research Center for Horticultural Crop Germplasm Creation and New Variety Breeding, experiment managers and technicians for their tireless work and support.

Conflicts of Interest: The authors declare that they have no conflict of interest.

\section{References}

1. Jones, J.D.; Dangl, J.L. The plant immune system. Nature 2006, 444, 323-329. [CrossRef]

2. Cook, D.E.; Mesarich, C.H.; Thomma, B.P. Understanding plant immunity as a surveillance system to detect invasion. Annu. Rev. Phytopathol. 2015, 53, 541-563. [CrossRef]

3. Van der Burgh, A.M.; Joosten, M. Plant Immunity: Thinking Outside and Inside the Box. Trends Plant Sci. 2019, $24,587-601$. [CrossRef] [PubMed]

4. Biere, A.; Goverse, A. Plant-Mediated Systemic Interactions Between Pathogens, Parasitic Nematodes, and Herbivores Aboveand Belowground. Annu. Rev. Phytopathol. 2016, 54, 499-527. [CrossRef] [PubMed]

5. Ezawa, T.; Saito, K. How do arbuscular mycorrhizal fungi handle phosphate? New insight into fine-tuning of phosphate metabolism. New Phytol. 2018, 220, 1116-1121. [CrossRef] [PubMed]

6. Almario, J.; Jeena, G.; Wunder, J.; Langen, G.; Zuccaro, A.; Coupland, G.; Bucher, M. Root-associated fungal microbiota of nonmycorrhizal Arabis alpina and its contribution to plant phosphorus nutrition. Proc. Natl. Acad. Sci. USA 2017, 114, E9403-E9412. [CrossRef]

7. Larriba, E.; Jaime, M.D.; Nislow, C.; Martin-Nieto, J.; Lopez-Llorca, L.V. Endophytic colonization of barley (Hordeum vulgare) roots by the nematophagous fungus Pochonia chlamydosporia reveals plant growth promotion and a general defense and stress transcriptomic response. J. Plant Res. 2015, 128, 665-678. [CrossRef]

8. Gams, W.; Zare, R. A revision of Verticillium sect. Prostrata. III. Generic classification. Nova Hedwig. 2001, 72, 329-337. [CrossRef]

9. Escudero, N.; Lopez-Llorca, L.V. Effects on plant growth and root-knot nematode infection of an endophytic GFP transformant of the nematophagous fungus Pochonia chlamydosporia. Symbiosis 2012, 57, 33-42. [CrossRef]

10. Tobin, J.D.; Haydock, P.P.J.; Hare, M.C.; Woods, S.R.; Crump, D.H. Effect of the fungus Pochonia chlamydosporia and fosthiazate on the multiplication rate of potato cyst nematodes (Globodera pallida and G. rostochiensis) in potato crops grown under UK field conditions. Biol. Control 2008, 46, 194-201. [CrossRef]

11. Silva, S.D.; Carneiro, R.; Faria, M.; Souza, D.A.; Monnerat, R.G.; Lopes, R.B. Evaluation of Pochonia chlamydosporia and Purpureocillium lilacinum for Suppression of Meloidogyne enterolobii on Tomato and Banana. J. Nematol. 2017, 49, 77-85. [CrossRef]

12. Wang, K.; Riggs, R.D.; Crippen, D. Isolation, Selection, and Efficacy of Pochonia chlamydosporia for Control of Rotylenchulus reniformis on Cotton. Phytopathology 2005, 95, 890-893. [CrossRef]

13. Dallemole-Giaretta, R.; Freitas, L.G.; Lopes, E.A.; Pereira, O.L.; Zooca, R.J.F.; Ferraz, S. Screening of Pochonia chlamydosporia Brazilian isolates as biocontrol agents of Meloidogyne javanica. Crop Prot. 2012, 42, 102-107. [CrossRef]

14. Viggiano, J.R.; de Freitas, L.G.; Lopes, E.A. Use of Pochonia chlamydosporia to control Meloidogyne javanica in cucumber. Biol. Control 2014, 69, 72-77. [CrossRef]

15. Maciá-Vicente, J.G.; Rosso, L.C.; Ciancio, A.; Jansson, H.B.; Lopez-Llorca, L.V. Colonisation of barley roots by endophytic Fusarium equiseti and Pochonia chlamydosporia: Effects on plant growth and disease. Ann. Appl. Biol. 2009, 155, 391-401. [CrossRef]

16. Bordallo, J.J.; Lopez-Llorca, L.V.; Jansson, H.-B.; Salinas, J.; Persmark, L.; Asensio, L. Colonization of plant roots by egg-parasitic and nematode-trapping fungi. New Phytol. 2001, 154, 491-499. [CrossRef] [PubMed]

17. Manzanilla-López, R.H.; Esteves, I.; Powers, S.J.; Kerry, B.R. Effects of crop plants on abundance of Pochonia chlamydosporia and other fungal parasites of root-knot and potato cyst nematodes. Ann. Appl. Biol. 2011, 159, 118-129. [CrossRef]

18. Zavala-Gonzalez, E.A.; Rodriguez-Cazorla, E.; Escudero, N.; Aranda-Martinez, A.; Martinez-Laborda, A.; Ramirez-Lepe, M.; Vera, A.; Lopez-Llorca, L.V. Arabidopsis thaliana root colonization by the nematophagous fungus Pochonia chlamydosporia is modulated by jasmonate signaling and leads to accelerated flowering and improved yield. New Phytol. 2017, 213, 351-364. [CrossRef] 
19. Zavala-Gonzalez, E.A.; Escudero, N.; Lopez-Moya, F.; Aranda-Martinez, A.; Exposito, A.; Ricaño-Rodríguez, J.; Naranjo-Ortiz, M.A.; Ramírez-Lepe, M.; Lopez-Llorca, L.V. Some isolates of the nematophagous fungus Pochonia chlamydosporia promote root growth and reduce flowering time of tomato. Ann. Appl. Biol. 2015, 166, 472-483. [CrossRef]

20. Monfort, E.; Lopez-Llorca, L.V.; Jansson, H.B.; Salinas, J.; Park, J.O.; Sivasithamparam, K. Colonisation of seminal roots of wheat and barley by egg-parasitic nematophagous fungi and their effects on Gaeumannomyces graminis var. tritici and development of root-rot. Soil Biol. Biochem. 2005, 37, 1229-1235. [CrossRef]

21. Rosso, L.C.; Colagiero, M.; Salatino, N.; Ciancio, A. Observations on the effect of trophic conditions on Pochonia chlamydosporiagene expression. Ann. Appl. Biol. 2014, 164, 232-243. [CrossRef]

22. Ghahremani, Z.; Escudero, N.; Saus, E.; Gabaldon, T.; Javier Sorribas, F. Pochonia chlamydosporia Induces Plant-Dependent Systemic Resistance to Meloidogyne incognita. Front. Plant Sci. 2019, 10, 945. [CrossRef]

23. Lin, R.; Qin, F.; Shen, B.; Shi, Q.; Liu, C.; Zhang, X.; Jiao, Y.; Lu, J.; Gao, Y.; Suarez-Fernandez, M.; et al. Genome and secretome analysis of Pochonia chlamydosporia provide new insight into egg-parasitic mechanisms. Sci. Rep. 2018, 8, 1123-1139. [CrossRef]

24. Lopez-Llorca, L.V.; Bordallo, J.J.; Salinas, J.; Monfort, E.; Lopez-Serna, M.L. Use of light and scanning electron microscopy to examine colonisation of barley rhizosphere by the nematophagous fungus Verticillium chlamydosporium. Int. Res. Rev. J. Microsc. 2002, 33, 61-67. [CrossRef]

25. Blazquez, M.A.; Nelson, D.C.; Weijers, D. Evolution of Plant Hormone Response Pathways. Annu. Rev. Plant Biol. 2020, 71, 327-353. [CrossRef] [PubMed]

26. Wondafrash, M.; Van Dam, N.M.; Tytgat, T.O. Plant systemic induced responses mediate interactions between root parasitic nematodes and aboveground herbivorous insects. Front. Plant Sci. 2013, 4, 87. [CrossRef]

27. Pieterse, C.M.; Leon-Reyes, A.; Van der Ent, S.; Van Wees, S.C. Networking by small-molecule hormones in plant immunity. Nat. Chem. Biol. 2009, 5, 308-316. [CrossRef] [PubMed]

28. Favery, B.; Quentin, M.; Jaubert-Possamai, S.; Abad, P. Gall-forming root-knot nematodes hijack key plant cellular functions to induce multinucleate and hypertrophied feeding cells. J. Insect Physiol. 2016, 84, 60-69. [CrossRef] [PubMed]

29. Gheysen, G.; Mitchum, M.G. Phytoparasitic Nematode Control of Plant Hormone Pathways. Plant Physiol. 2019, 179, 1212-1226. [CrossRef] [PubMed]

30. Kammerhofer, N.; Radakovic, Z.; Regis, J.M.; Dobrev, P.; Vankova, R.; Grundler, F.M.; Siddique, S.; Hofmann, J.; Wieczorek, K. Role of stress-related hormones in plant defence during early infection of the cyst nematode Heterodera schachtii in Arabidopsis. New Phytol. 2015, 207, 778-789. [CrossRef] [PubMed]

31. Yoshioka, K.; Kachroo, P.; Tsui, F.; Sharma, S.B.; Shah, J.; Klessig, D.F. Environmentally sensitive, SA-dependent defense responses in the cpr22 mutant of Arabidopsis. Plant J. 2001, 226, 447-459. [CrossRef] [PubMed]

32. Uknes, S.; Dincher, S.; Friedrich, L.; Negrotto, D.; Williams, S.; Thompson-Taylor, H.; Potter, S.; Ward, E.; Ryals, J. Regulation of Pathogenesis-Related Protein-1a Gene Expression in Tobacco. Plant Cell 1993, 5, 159-169.

33. Pallas, J.A.; Paiva, N.L.; Lamb, C.; Dixon, R. Tobacco plants epigenetically suppressed in phenylalanine ammonia-lyase expression do not develop systemic acquired resistance in response to infection by tobacco mosaic virus. Plant J. 1996, 10, 281-293. [CrossRef]

34. Spoel, S.H.; Koornneef, A.; Claessens, S.M.; Korzelius, J.P.; Van Pelt, J.A.; Mueller, M.J.; Buchala, A.J.; Metraux, J.P.; Brown, R.; Kazan, K.; et al. NPR1 modulates cross-talk between salicylate- and jasmonate-dependent defense pathways through a novel function in the cytosol. Plant Cell 2003, 15, 760-770. [CrossRef]

35. Wasternack, C.; Stenzel, I.; Hause, B.; Hause, G.; Kutter, C.; Maucher, H.; Neumerkel, J.; Feussner, I.; Miersch, O. The wound response in tomato-role of jasmonic acid. J Plant Physiol. 2006, 163, 297-306. [CrossRef] [PubMed]

36. Medeiros, H.A.; Araujo Filho, J.V.; Freitas, L.G.; Castillo, P.; Rubio, M.B.; Hermosa, R.; Monte, E. Tomato progeny inherit resistance to the nematode Meloidogyne javanica linked to plant growth induced by the biocontrol fungus Trichoderma atroviride. Sci. Rep. 2017, 7, 40216-40229. [CrossRef] [PubMed]

37. Martinez-Medina, A.; Fernandez, I.; Lok, G.B.; Pozo, M.J.; Pieterse, C.M.; Van Wees, S.C. Shifting from priming of salicylic acidto jasmonic acid-regulated defences by Trichoderma protects tomato against the root knot nematode Meloidogyne incognita. New Phytol. 2017, 213, 1363-1377. [CrossRef] [PubMed]

38. Tolba, S.R.T.; Rosso, L.C.; Pentimone, I.; Colagiero, M.; Moustafa, M.M.A.; Elshawaf, I.I.S.; Bubici, G.; Prigigallo, M.I.; Ciancio, A. Root Endophytism by Pochonia chlamydosporia Affects Defense-Gene Expression in Leaves of Monocot and Dicot Hosts under Multiple Biotic Interactions. Plants 2021, 10, 718. [CrossRef]

39. Khatabi, B.; Molitor, A.; Lindermayr, C.; Pfiffi, S.; Durner, J.; von Wettstein, D.; Kogel, K.H.; Schafer, P. Ethylene supports colonization of plant roots by the mutualistic fungus Piriformospora indica. PLoS ONE 2012, 7, e35502. [CrossRef]

40. Pentimone, I.; Lebron, R.; Hackenberg, M.; Rosso, L.C.; Colagiero, M.; Nigro, F.; Ciancio, A. Identification of tomato miRNAs responsive to root colonization by endophytic Pochonia chlamydosporia. Appl. Microbiol. Biotechnol. 2018, 102, 907-919. [CrossRef]

41. Lin, R.; Liu, C.; Shen, B.; Bai, M.; Ling, J.; Chen, G.; Mao, Z.; Cheng, X.; Xie, B. Analysis of the complete mitochondrial genome of Pochonia chlamydosporia suggests a close relationship to the invertebrate-pathogenic fungi in Hypocreales. BMC Microbiol. 2015, 15, 5. [CrossRef] [PubMed]

42. Shen, B. The Functional Research of Extracellular Proteases Related to Nematode Egg Parasitism in Pochonia chlamydosporia. Ph.D. Thesis, Hunan Agricultural University, Changsha, China, 1 June 2015.

43. Howe, G.A.; Lightner, J.; Browse, J.; Ryan, C.A. An Octadecanoid Pathway Mutant (JL5) of Tomato 1s Compromised in Signaling for Defense against lnsect Attack. Plant Cell 1996, 8, 2067-2077. [PubMed] 
44. Brading, P.; Hammond-Kosack, K.; Parr, A.; Jones, J. Salicylic acid is not required for Cf-2- and Cf-9-dependent resistance of tomato to Cladosporium fulvum. Plant J. 2000, 23, 305-318. [CrossRef]

45. Murphy, J.F.; Reddy, M.S.; Ryu, C.M.; Kloepper, J.W.; Li, R. Rhizobacteria-Mediated Growth Promotion of Tomato Leads to Protection Against Cucumber mosaic virus. Phytopathology 2003, 93, 1301-1307. [CrossRef]

46. Song, W.T.; Zhou, L.G.; Yang, C.Z.; Cao, X.D.; Zhang, L.Q.; Liu, X.L. Tomato Fusarium wilt and its chemical control strategies in a hydroponic system. Crop. Prot. 2004, 23, 243-247. [CrossRef]

47. Tans-Kersten, J.; Brown, D.; Allen, C. Swimming motility, a virulence trait of Ralstonia solanacearum, is regulated by FlhDC and the plant host environment. Mol. Plant Microbe Interact. 2004, 17, 686-695. [CrossRef]

48. Lopez-Raez, J.A.; Verhage, A.; Fernandez, I.; Garcia, J.M.; Azcon-Aguilar, C.; Flors, V.; Pozo, M.J. Hormonal and transcriptional profiles highlight common and differential host responses to arbuscular mycorrhizal fungi and the regulation of the oxylipin pathway. J. Exp. Bot. 2010, 61, 2589-2601. [CrossRef]

49. El Oirdi, M.; El Rahman, T.A.; Rigano, L.; El Hadrami, A.; Rodriguez, M.C.; Daayf, F.; Vojnov, A.; Bouarab, K. Botrytis cinerea manipulates the antagonistic effects between immune pathways to promote disease development in tomato. Plant Cell 2011, 23, 2405-2421. [CrossRef]

50. Liu, X.; Meng, G.; Wang, M.; Qian, Z.; Zhang, Y.; Yang, W. Tomato SlPUB24 enhances resistance to Xanthomonas euvesicatoria pv. perforans race T3. Hortic. Res. 2021, 8, 30. [CrossRef]

51. Omomowo, O.I.; Babalola, O.O. Bacterial and Fungal Endophytes: Tiny Giants with Immense Beneficial Potential for Plant Growth and Sustainable Agricultural Productivity. Microorganisms 2019, 7, 481. [CrossRef] [PubMed]

52. Zamioudis, C.; Pieterse, C.M. Modulation of host immunity by beneficial microbes. Mol. Plant-Microbe Interact. 2011, 25, 139-150. [CrossRef]

53. Esteves, I.; Peteira, B.; Atkins, S.D.; Magan, N.; Kerry, B. Production of extracellular enzymes by different isolates of Pochonia chlamydosporia. Mycol. Res. 2009, 113, 867-876. [CrossRef]

54. Morton, C.O.; Mauchline, T.H.; Kerry, B.R.; Hirsch, P.R. PCR-based DNA fingerprinting indicates host-related genetic variation in the nematophagous fungus Pochonia chlamydosporia. Mycol. Res. 2003, 107, 198-205. [CrossRef]

55. Lahrmann, U.; Strehmel, N.; Langen, G.; Frerigmann, H.; Leson, L.; Ding, Y.; Scheel, D.; Herklotz, S.; Hilbert, M.; Zuccaro, A Mutualistic root endophytism is not associated with the reduction of saprotrophic traits and requires a noncompromised plant innate immunity. New Phytol. 2015, 207, 841-857. [CrossRef]

56. Lagunas, B.; Schafer, P.; Gifford, M.L. Housing helpful invaders: The evolutionary and molecular architecture underlying plant root-mutualist microbe interactions. Exp. Bot. 2015, 66, 2177-2186. [CrossRef] [PubMed]

57. Hause, B.; Schaarschmidt, S. The role of jasmonates in mutualistic symbioses between plants and soil-born microorganisms. Phytochemistry 2009, 70, 1589-1599. [CrossRef]

58. Miche, L.; Battistoni, F.; Gemmer, S.; Belghazi, M.; Reinhold-Hurek, B. Upregulation of jasmonate-inducible defense proteins and differential colonization of roots of Oryza sativa cultivars with the endophyte Azoarcus sp. Mol. Plant-Microbe Interact. 2006, 19, 502-511. [CrossRef]

59. Tejeda-Sartorius, M.; Martinez de la Vega, O.; Delano-Frier, J.P. Jasmonic acid influences mycorrhizal colonization in tomato plants by modifying the expression of genes involved in carbohydrate partitioning. Plant Physiol. 2008, 133, 339-353. [CrossRef] [PubMed]

60. Dias-Arieira, C.R.; Santana, S.D.; de Freitas, L.G.; da Cunha, T.P.L.; Biela, F.; Puerari, H.H.; Chiamolera, F.M. Efficiency of Pochonia chlamydosporia in Meloidogyne incognita control in lettuce crop (Lactuca sativa L.). J. Food Agric. Environ. 2011, 9, 561-563.

61. Macia-Vicente, J.G.; Jansson, H.B.; Mendgen, K.; Lopez-Llorca, L.V. Colonization of barley roots by endophytic fungi and their reduction of take-all caused by Gaeumannomyces graminis var. tritici. Can. J. Microbiol. 2008, 54, 600-609. [CrossRef]

62. Sahebani, N.; Hadavi, N. Biological control of the root-knot nematode Meloidogyne javanica by Trichoderma harzianum. Soil Biol. Biochem. 2008, 40, 2016-2020. [CrossRef]

63. Pieterse, C.M.; Zamioudis, C.; Berendsen, R.L.; Weller, D.M.; Van Wees, S.C.; Bakker, P.A. Induced systemic resistance by beneficial microbes. Annu. Rev. Phytopathol. 2014, 52, 347-375. [CrossRef] [PubMed]

64. Nawrocka, J.; Malolepsza, U. Diversity in plant systemic resistance induced by Trichoderma. Biol. Control 2013, 67, 149-156. [CrossRef]

65. Salas-Marina, M.A.; Silva-Flores, M.A.; Uresti-Rivera, E.E.; Castro-Longoria, E.; Herrera-Estrella, A.; Casas-Flores, S. Colonization of Arabidopsis roots by Trichoderma atroviride promotes growth and enhances systemic disease resistance through jasmonic acid/ethylene and salicylic acid pathways. European Journal of Plant Pathology 2011, 131, 15-26. [CrossRef]

66. Rotenberg, D.; Thompson, T.S.; German, T.L.; Willis, D.K. Methods for effective real-time RT-PCR analysis of virus-induced gene silencing. J. Virol. Methods 2006, 138, 49-59. [CrossRef]

67. Sarmento, R.A.; Lemos, F.; Bleeker, P.M.; Schuurink, R.C.; Pallini, A.; Oliveira, M.G.; Lima, E.R.; Kant, M.; Sabelis, M.W.; Janssen, A. A herbivore that manipulates plant defence. Ecol. Lett. 2011, 14, 229-236. [CrossRef] [PubMed]

68. Gayoso, C.; Pomar, F.; Novo-Uzal, E.; Merino, F.; de Ilarduya, O.M. The Ve-mediated resistance response of the tomato to Verticillium dahliae involves $\mathrm{H}_{2} \mathrm{O}_{2}$, peroxidase and lignins and drives PAL gene expression. BMC Plant. Biol. 2010, 10, 232. [CrossRef] [PubMed]

69. Uppalapati, S.R.; Ayoubi, P.; Weng, H.; Palmer, D.A.; Mitchell, R.E.; Jones, W.; Bender, C.L. The phytotoxin coronatine and methyl jasmonate impact multiple phytohormone pathways in tomato. Plant. J. 2005, 42, 201-217. [CrossRef] [PubMed] 